\section{It Takes a Village of Mentors Alan Lesgold}

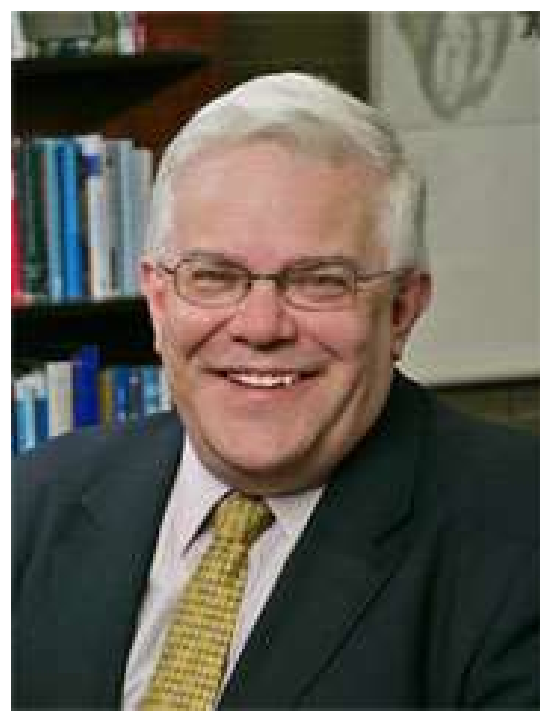

Reflecting on an extremely rewarding career, I am struck by how much it depended on a series of mentors - and of course on some lucky breaks. In this chapter, I first provide some personal history and then consider lessons I have learned along the way.

\section{Early Life and Schooling}

I provide some details about my early life for two reasons. First, it will be evident that many fortunate accidents combined to help me get a good start. Second, it probably was easier for those accidents to occur back then than today. My major concern has been to help our education systems find ways to restore the kind of supportive environment that offered me opportunities in spite of being from a family that was not at all wealthy. I am a third generation American. My grandparents all grew up in the Pale of Settlement, the western edge of the Russian Empire where Jews were permitted to live. Almost all Jews in that region were poor, with no social support network beyond their Jewish neighbors, and they were discriminated against substantially. One of my grandparents lived with a relative in a different town than her parents and some siblings, because my great grandparents simply could not support all of them. My father's parents came to America in 1907, settling briefly in Delafield, Wisconsin and then moving to Milwaukee. My mother's father was subsidized to come to the U.S. in 1912 by Jacob Schiff, a wealthy New York businessman who feared that Jews would suffer if they became too concentrated in New York. So, Zaide (my grandfather) entered through Galveston in order to get part of his way paid by Mr. Schiff. The Russian Revolution and World War I intervened before he could bring my grandmother and uncle over in 1918. Eventually, they also ended up in Milwaukee where my parents met and I was born.

Milwaukee was a city run by socialists until I turned 15. As a result of that, we had two years of kindergarten and a general atmosphere of socially shared responsibility. There were boxes of sand and ashes on street corners, with shovels in them. On icy days, people were expected to get out of their cars and shovel a little grit on any slick spots to protect their neighbors. Within both the family and the community, I had the good fortune to be born in a very nurturing place.

My father was the first person in his family to attend college, and he struggled at first. He worked more than full time while also in school full time, and that did not work out. So, he had to leave school for a year. Quite possibly, the added stress and financial need created by my recent birth contributed to all of that. But, he returned to school and graduated in 1948 from the 
University of Wisconsin with a degree in electrical engineering.

My entry into the world was not

without some stresses. I had a genetic problem, hypertrophic pyloric stenosis (an overgrowth of muscle constricting the exit valve of the stomach), and I ended up being one of the first children to have that fixed surgically in the months shortly after my birth. When I caught pneumonia after surgery, I became one of the first civilians to be saved by penicillin, which had been reserved for military use during World War II. The advanced (for its time) health care that saved my life was affordable back then; today a poor child with the same problem could die, even though the treatment is now more routine than it was in January 1946. While my good fortune started early, it was not financial good fortune. My parents, two brothers, grandfather, and I all lived in a three-bedroom house for most of my childhood, so my two brothers and I shared a single small bedroom. It was good preparation for the population density of dormitory life at college.

From the beginning, my father taught me that one could solve large problems if one persisted. Indeed, to this day I feel a little guilty if I hire an electrician or plumber to do something that he taught me to do myself. Even at the age of 3, I was recruited to help my father build our first TV set, shortly after Milwaukee got its first television station. My job was to find the right resistors from a large pile. Resistors were coded with colored stripes that indicated their resistance value. My father was color blind, so I had to match the colors associated with a particular resistance value to the stripes on the resistors and then hand him the one he needed next. The resulting TV set worked throughout my childhood; I occasionally was sent to buy replacement vacuum tubes. As an adolescent, when I briefly was interested in amateur radio, my father and I built a radio transmitter rather than buying one. Dad had become an expert in magnetics and power supplies; he even designed a few components for the Lunar Lander that still remain on the moon (fortunately, there is an extra lander in the Smithsonian so I could show my kids the parts grandpa designed). I was no electronics whiz, but I did feel that I understood the environment in which I lived and could shape it to my needs.

My parents were very nurturing, provided considerable intellectual stimulation, and also were fully committed to public education. When I was offered a full scholarship to the best private high school in the region; they refused to send me there because they didn't see us as being among the privileged. They did send me to a variety of extracurricular opportunities that broadened my formation substantially. So, for example, I was in an after-school program for high school students that exposed me to top scientists periodically. I especially remember, for example, hearing a presentation on peaceful uses of nuclear energy by Edward Teller at which he showed movies to support his call for use of nuclear devices to dig a bigger canal across Central America. As I saw the side of a mountain rippling during a buried nuclear test, I remember thinking of the line from Psalm 114: "the mountains danced like rams." While uneasy about Teller's specific goal, I certainly grew up thinking that science and engineering could be extremely powerful forces for improving our lives.

My interest in research also was stimulated by a summer National Science Foundation (NSF) workshop experience. At the age of 15 , between my junior and senior years of high school, I attended an NSF program at Oregon State University. My parents had no concerns about me flying alone to Corvallis and being in that program for a few weeks, over 2000 miles from home, because daily life back then assumed that people took care of one another, including strangers. The NSF program gave me an intuitive grounding for calculus, and exposure to the beginnings of computer science (I had the chance to build simple computers from relays taken out of slot machines that the local sheriff confiscated from bars). It was the first of several lucky breaks that set the stage for me to use 
information technology throughout my career and later to teach myself something about artificial intelligence. ${ }^{1}$

When it came time to go to college, my initial plan had been to attend the University of Wisconsin in Madison. However, my parents discouraged this (in their later years, they insisted that they did not). As a result, another positive force of my upbringing, having a wonderful girlfriend, eventually was lost, as she did go to UW. As this drama was unfolding, I received a letter from Michigan State University (MSU), informing me that they had established a number of scholarships under the National Merit program that were available to students who specified MSU as their first choice. This was part of an effort to attract strong students there. I made them my first choice, and ended up enrolling at MSU. This had two major effects on my life. First, the woman who became my wife was similarly attracted to MSU from Kingman, Arizona, eventually leading to us becoming one of the first pair of Merit scholars to be crossbred.

Second, I entered the MSU Honors College, which was in its eleventh year. This was important because Honors College students at MSU could design their own academic programs, subject only to approval of an assigned advisor. This allowed me to take a mix of graduate and undergraduate courses, skip such things as introductory psychology as I pursued a psychology major, and otherwise learn a lot in a more rigorous environment. It also probably primed me to seek a student job that had better prospects for affording learning opportunities than the first on-campus job that I had.

Knowing that I had two younger brothers and that college costs were a strain for my parents, I worked throughout my undergraduate years. Initially, MSU provided a job in the dormitory food service. It was my privilege to operate the world's largest garbage disposal. For this work, I was paid
95 cents per hour. After a few weeks, I was pretty sure that I had learned about as much as I would from this particular job, though it really was not all that bad (the young are less prone to dishpan hands). One day, though, I was reading the student newspaper and saw a small ad placed by Prof. Charles Wrigley, a political psychologist who had formed the Computer Institute for Social Science Research. The ad indicated that there were jobs for Honors College students in which they would be trained to do computer programming. Moreover, these jobs paid $\$ 2.50$ per hour. Needless to say, this seemed like something I should check out.

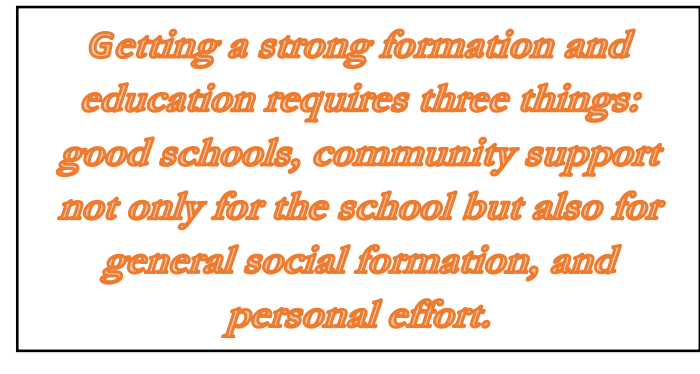

I remember a few things about my initial interview with Charles. He was from New Zealand and had a British education, but his knowledge of how MSU students lived was a little sketchy. When I told him I worked in the food service, he said "so, your job is to take pies out from the kitchen to the students?" I filled him in on the technological depths I actually had reached. He then explained that he was hoping that I could join some graduate students in the task of writing programs to do multivariate statistical analyses. Specifically, he was interested in doing factor analyses of a large body of data collected on early Peace Corps volunteers. He then took a pad of paper, and explained, to someone who had no background in statistics or linear algebra, the basic ideas behind factor analysis.

Amazingly, it all made sense and I was able to follow his explanations.

For the remainder of my undergraduate days, three and one-half years, I worked in Prof. Wrigley's institute.

\footnotetext{
${ }^{1}$ Recently, I learned from Edward Reingold, who attended the Oregon State program with me, that at least seven attendees that year became either professors or scientists in research institutes (some attendees could not be located after over 50 years, so the total could be higher).
} 
The core task we pursued - and I was one of many involved - was to write a package of software to do multivariate statistics (programs like SPSS came a few years after I graduated; we essentially built a precursor from scratch). So, my undergraduate job ended up teaching me computer programming and multivariate statistics at the cost of limiting my expertise in quickly removing peanut butter from dishes before they went through a dishwashing machine. My mentor from day to day in this effort was Frank Sim, a graduate student in sociology. I also learned a lot about scaling from Louis McQuitty, who at the time was dean of social sciences and a co-founder of the Computer Institute for Social Science Research. And of course, Charles Wrigley was a wonderful first mentor.

There was another experience that occurred as a result of my work in the Institute. In 1964, when I was a sophomore, I was asked to teach a course for high school students in FORTRAN programming. This was my first teaching experience, and it went reasonably well, I think. A couple years later, a national magazine had an article suggesting that this was the first programming class ever for high school students, but I am pretty sure someone at MIT had done it earlier. Overall, Michigan State provided incredible opportunities. I got a good grounding in psychology, including some graduate courses. I learned the essentials of multivariate statistics and scaling. I learned both how to program and that I was quite capable of getting computers to do things.

Computers were harder to use back then. For example, in order to carry out a number of statistical analyses on the Peace Corps database or the U. S. Census database, we needed to develop algorithms that were efficient in their relative demands on huge data tapes versus very limited core memory. Reading data from tape was extremely slow, so we developed schemes to pre-screen the set of analyses that a user wanted to perform. Our program would figure out how many analyses could be done on a single pass through the data tape and then accumulate the various sums of squares and cross-products needed for those analyses into core memory all at once rather than doing the analyses one at a time. By limiting the number of passes through tape (actually, for the census it was a set of several large tapes that had to be mounted by hand one after another), we made the program run a lot faster. Years later when I took an operations research class and studied formal techniques for optimization, I learned that I could have done better at this than my intuitions suggested at the time. I also learned from experience with people who used the statistical programs that it was worthwhile, before printing them, to sort the analyses to match the original order requested by the researcher. These experiences remind me that many students can stretch far beyond what we routinely ask of them. Fortunately, Charles Wrigley invested in stretching me.

It is somewhat amusing as a dean of education to recall that MSU also provided the only teaching certification I have ever received. There was, at the time, a requirement that students complete three recreational physical education classes in order to graduate. My sporting interests back then were limited. So, I succumbed to the temptation to take, as one of my requirements, a course in trap shooting. This actually provided a lot of exercise, since the firing range was a couple miles away from the campus, in a direction without mass transit. I learned how to hit the broad side of a barn, and while many of the clay pigeons released when I was shooting were able to be recycled, I apparently accomplished what was required in the course. To my surprise, about a month later, the State of Michigan issued me credentials as a certified hunter safety instructor, which remains my only government-issued teaching credential.

Another important set of experiences at MSU was the opportunity to take several courses in logic and philosophy of science from Gerald Massey. I was probably in Jerry's first undergraduate class, and he taught me a lot. Later, when I got to 
the University of Pittsburgh, Jerry was my colleague and chaired Pitt's Department of Philosophy. Eventually, when I helped found Pitt's Intelligent Systems Program, I helped hire Jerry's first PhD student, Bruce Buchanan. In some ways, the academy is a small world.

In 1966, during my junior year, I began to think about next steps after MSU. With advice from Charles Wrigley and others, I ended up applying to psychology programs at Michigan, Stanford, Penn, and Wisconsin. That was about the order of my preference as well. Michigan had strengths in quantitative psychology and also in the emerging space of information processing approaches to cognition, precursors to the cognitive psychology that would be evolving as I went through graduate school. Stanford was in the midst of its era of mathematical psychology. Initially, I planned to attend the University of Michigan. I was intrigued by the thinking of Walter Reitman and also had connected with Clyde Coombs, so both information processing ideas and quantitative methods were attractions there.

Once again, as in my choice of undergraduate institutions, chance intervened. Sharon and I were planning to be married just before graduation, so the choice was now a two-person matter. Just before the deadline for accepting offers, Stanford wrote Sharon indicating that she had been awarded a Shell Fifth Year Merit Scholarship. Now, after four years at MSU that included many subzero days and a three-foot snowfall, this Arizona girl really was ready for someplace warmer. In my mind, the opportunities at Michigan and at Stanford were both exciting, so at the last minute we decided to go to Stanford. The graduate student who had been assigned to work with me initially in Charles Wrigley's Institute, Frank Sim, was already at Stanford as an assistant professor of sociology. So, I was going to Stanford already knowing someone there.

Frank soon asked whether I would like a summer job at Stanford before I started my studies there in September. That seemed like a great idea, and what was needed there was to translate and expand statistical software programs to run on Stanford's new computer, the IBM 360. Back in those days, changing computers often meant rewriting software substantially. Especially noteworthy that summer was the opportunity to get to know Sanford Dornbusch. Sandy, a fine sociologist, was in the midst of his study of high school students at the time, and one of his findings has stayed with me since then. He found that students doing less well in school believed that they were working harder and longer on their homework than the better students, but that in fact the better students were putting in more time. The lesson for me was not the one that would emerge later in Carol Dweck's work (that less successful students often believe that learning is due to aptitude rather than effort) but rather that students doing poorly really don't have a good idea of how much they are learning or of how hard it will be to learn more.

Decades later, while studying how children learn to read (or don't), I would return to this basic idea that students who struggle need help both in recognizing their successes and in gauging how much effort to invest in learning.

A second, more poignant, lesson came that summer as well. One day, Frank told me that he was going to leave Stanford to go to Penn State. Now, it takes very little time for someone from the upper Midwest to figure out that Stanford is part of paradise. So, I asked Frank what had prompted him to leave The Farm for Happy Valley. What he told me was another important life lesson that I have passed on several times as dean: "Well, Alan, when you walk into your chairman's office and tell him you just got a great offer, be prepared for him to shake your hand and wish you well." Painfully, Frank died quite young. I've always wondered whether he would have done better being treated at Stanford Hospital. Late in the summer, it seemed appropriate to get to know some of the people in psychology at Stanford, since I was about to begin my graduate studies with them. I learned that the faculty and graduate 
students in mathematical psychology held a weekly research seminar on Friday afternoons, so I decided I should start going to that. As luck would have it, I picked a Friday when the faculty were having a farewell lunch for a visiting colleague. So, they all showed up quite mellow from that event. Gordon Bower, truly one of the finest and most humane mentors I have had, spotted me and inquired most exuberantly, "Who the hell are you?" I introduced myself and mentioned that he had been assigned as my advisor. So it was that I met the person who really taught me to be a professor.

Working with Gordon Bower was an incredible experience. He was, of course, an exceptional scientist, something recognized later with a National Medal of Science and other major accolades. He also was an exceptional writer and communicator. And, he was a great model of good research strategy. While I started out biased to do complex experiments that dealt with every possible subtlety that might arise, Gordon taught me to focus first on making sure that there was a core phenomenon that could be established strongly and without doubt and then to focus in on details. Regrettably, in the current age of micromanagement of research strategy in the grant making process, this lesson is sometimes lost. On the other hand, better statistical and data management tools now do allow initial studies to be larger in scale and consequently able to answer more questions. Mathematical psychology at Stanford back then was an intense intellectual effort. Absent powerful computers, theories were expressed as complex sets of equations which then were solved by hand. To be a good mathematical psychologist, one had to be an exceptional mathematician. Gordon Bower was one such person, and there were others, including Bill Estes, Dick Atkinson, Walter Kintsch, and especially Duncan Luce. Some were continuing members of the Stanford faculty and others were visitors. The overall level of mathematical analysis skill in psychologists at the time was quite incredible.

Stanford had a rule that every doctoral student had to complete four courses outside of the degree-granting department. This resulted in me taking courses from Pat Suppes, Mike Arbib, and some math and operations research faculty, filling in a lot of gaps in my mathematical expertise and further preparing me to learn about artificial intelligence. Stanford also required that the milestone exams comprehensives and dissertation - be chaired by someone outside the degreegranting department. My comps, as a result, allowed me to meet a bright young computational linguist, Roger Schank, from whom I also have learned on and off over the decades.

The years I spent at Stanford, 1967 to 1971 , were the period in which experimental psychologists were beginning to move from an associationist viewpoint anchored in behavior theory to an information processing viewpoint that would become the basis for cognitive science. It was a privilege to be doing this learning myself along with my teachers. Another student of Gordon Bower's, John Anderson, helped shape my thinking and that of many others during that period. John made the critical observation that knowledge could be represented by rules that captured what mental process should take place as a function of what content was currently active in memory. In essence, he moved the behavioral notion of connections between external stimuli and

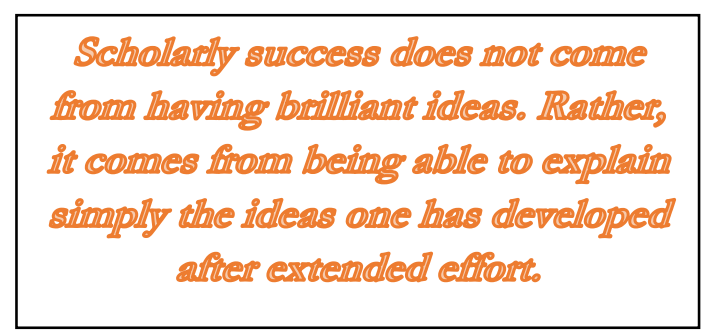

motor responses into the head, where the connections were between working memory content and mental (or physical) acts.

In a paper that few have read but that was of great importance, Pat Suppes 
(1969) showed that the rules Anderson was working with could capture the capability of any finite automaton. Any thinking that could be carried out by a computer could be captured by the system of rules Anderson used to capture cognition, and thus the task of cognitive psychology in large part was to establish how rules get learned. Moreover, Pat Suppes' theorem suggested that what can be understood about human thinking can be embodied in computer programs. From this beginning came the best of current learning theory as well as the foundations for intelligent tutoring systems.

Those Friday seminars were my first introduction to Stanford's psychology department and were continued throughout my four years there. Each week, a student or faculty member or visiting scholar would present their latest work, affording all of us another view of the evolution from statistical learning theory to cognitive psychology. It was the ultimate school for scholars as well as an intellectual paradise, even on the not-too-infrequent days when I could not follow the complex mathematical arguments fast enough and took most of the next week to figure out, even partially, what I had heard.

There were certain bonuses to working with Gordon Bower. He was an incredible crafter of both journal articles and oral presentations. And, Sharon Bower, his wife, was also available to bring the perspective of a drama coach to bear on our rehearsals before our debut presentations at professional meetings. Sharon's advice still comes to mind as I prepare and give presentations, especially her ability to focus on each sentence and ask: "what will the listener understand from what you just said." To this day, my only decent presentations are those I prepare using what she taught me.

Gordon had incredible writing skills in addition to his amazing mathematical and statistical ability. $\mathrm{He}$ would eyeball spreadsheets of data we showed him and, if he had trouble getting to sleep that night, he would appear the next day with a complete results section written, asking us to check the statistics, which were always very close to being perfect. He eyeballed the data during the day, wrote the results up without notes at night, and seldom was off, even on the detailed statistics, by more than a few percent. I did, after about twenty years of research experience, discover a few tricks to doing this, but the bottom line is that Gordon's understanding of distributions and probabilities was superb. At the same time, Gordon also modeled the importance of taking the time to properly prepare a presentation or article. He could have winged it on many occasions, but he didn't. We often got early drafts of presentations and papers for comments, and his questions about our presentations also modeled the kind of reflection needed to communicate well.

It would be nice to be able to say that by the time I left Stanford, I had learned both to do good research and to write it up well, but in reality it took me another decade to get even halfway decent at this, and it took additional mentors. It also is important to recognize that others at Stanford shaped my development as a scholar, including Dick Atkinson and Herb Clark, who also were on my doctoral committee and visiting scholars like Walter Kintsch and Jim Greeno. Each taught me a lot. Finally, there were other students, both of Gordon and of other faculty, who were an incredible source of wisdom. A number of them were Stanford classmates who later became colleagues in Pittsburgh at Pitt or Carnegie Mellon, including John Anderson, Pat Carpenter, Marcel Just, Lynn Cooper, Bobbi Klatzky, and Ruth Day. I could go on recalling additional classmates, but I surely would miss some. The quick summary is that the combination of incredible faculty and amazing fellow students made it much more likely that I would emerge from the graduate student experience on the path to doing some decent work.

There were other strokes of luck along the way as well. Recall that while I was a graduate student, the United States was fighting a war in Vietnam. In the midst of 
my studies, lottery numbers were issued by the Selective Service. One classmate, Gary Olson, got a low number, which meant he would be drafted. He was able to get a commission in the Navy and served his time as an officer at the New London submarine base. This allowed him to continue doing research part of the time and also to be certified as a hard hat diver.

My luck was a little different. I drew a borderline number that turned out to be low enough to be a problem. But, I was lucky. I had been a pretty chunky guy as an undergraduate, but early in my graduate studies, I began to lose weight. When called for a physical, I probably was eligible to serve. However, the person who measured my height concluded that I was about three inches shorter than I believe I was at the time (of course, the Army is always right, so I can't be sure). As luck would have it, my weight was a few pounds too high for a short person. I was worried that they would call me back and reach a conclusion more consistent with my own observations, so before leaving the place where they gave physicals, I got the Navy representative to endorse my physical with a statement that it was sufficient for a non-line officer's commission. Periodically, over the next few years, my draft board would ask me to have a physician report my weight. This was done accurately each time. However, the system never felt the need to reassess my height. So, I was able to complete my studies uninterrupted - something that probably was extremely helpful to any success that may have come along later.

As I approached the end of my studies at Stanford, I had two job interviews. One was at Oklahoma State, and they loved me - I suppose that I could have ended up later with fellow Stanford alumnus Bob Sternberg as my provost had I gone there. I also interviewed at Columbia. I fared less well there, perhaps because I gave the wrong answer when they asked me how much I liked New York. Then, some interactions began with the University of Pittsburgh. I forget the order of events, but within a short period, Jim Voss, who was on sabbatical from Pitt, stopped by to chat and I was invited by Bob Glaser to interview at Pitt. My interview was scheduled immediately before a conference being held at Pitt's Learning Research and Development Center (LDRC), and I was invited to stay for the conference. The resulting book from that meeting, edited by Tulving and Donaldson (1972), recorded the transition from associationist theories of learning to a cognitive view, at least for a major chunk of the experimental psychology world. Needless to say, I left the interview pretty convinced that Pitt was an important node in the experimental psychology research world. Among the researchers at that meeting, incidentally, was Gordon Bower. Given all these occurrences, it probably was inevitable that I would end up at Pitt. Like the accident of going to Stanford, this lucky break played a major role in whatever successes I have had as a scholar.

Having spent my graduate years amid the shift from associationist thinking to cognitive science, I have spent my professorial years in an institution that has become truly great and that is evolving to make important contributions to our world. In contrast to the dusty image of a neverchanging professoriate, my experiences have been with people who were strong scholars, respected the accumulated knowledge of earlier colleagues, but also were ready to challenge their own beliefs and to search for ways to make what they learned useful.

The early years at Pitt were extremely helpful. Bob Glaser was an excellent mentor and gave me conviction that research could indeed improve schooling. He also supported my sense of adventure (and modeled such a sense

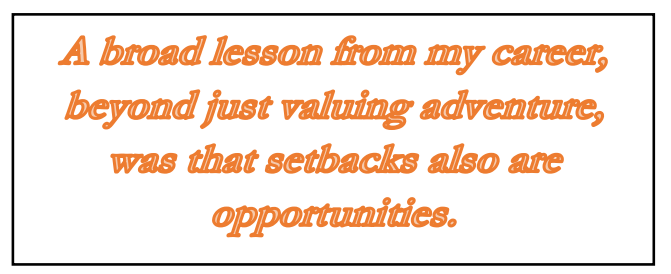


himself), which helped me make some of the shifts in my scholarly work over the later years. Bob's own protégé, Lauren Resnick, also taught me a lot. She, too, took educational research seriously and shared with Bob a strong sense of responsibility for taking what one learns and helping the world make use of it. While earlier mentors taught me that I could push myself to think really deeply, Bob and Lauren taught me that with further effort I could push my ideas far enough to be useful in learning and training. They also taught me a lot about the leadership of academic enterprises (I was their associate director for fourteen years before becoming a dean), which helped years later when I became a dean.

Before discussing some of my work and the lessons to be drawn from it, I should add one more historical note that might be helpful to future colleagues. While Pitt was an adventurous place, especially within the LDRC, no university operates with uniformity in any respect. When it was time to be considered for tenure, my record was adequate but probably not the strongest to pass through Pitt. Nonetheless, the faculty in the psychology department, where my tenure stream appointment was located, voted clearly in favor of tenure. However, the chair turned in a negative recommendation, believing that further movement of the department toward applied research was a bad idea (and I certainly had made clear by then my interest in seeing my work have impact in real educational settings). So, I was not granted tenure. Bob Glaser was kind enough to keep me on as a research assistant professor at LRDC.

Several years later, the University of Delaware offered me a tenured full professorship. By then, Pitt's psychology department had a new chair. I turned down his offer of a tenured associate professor position, and was about to accept the offer from Delaware when Pitt made me a full professor with tenure. So, I have never been an associate professor. Had I gone to Delaware, my work would have been more heavily in educational technology, but it

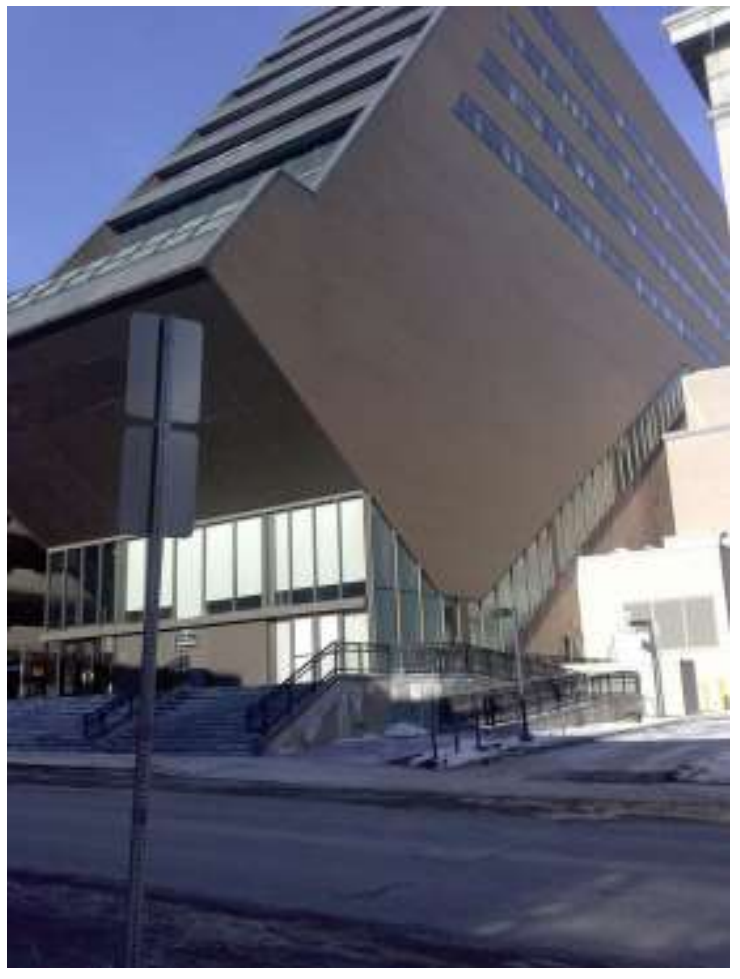

Learning and Research Development Center (LDRC)

probably would not have been as adventurous as it became at Pitt with a joint appointment in the LRDC.

\section{Lessons Learned Beginning My Career}

My assignment in this chapter is not only to provide some background about my career but also to pass on lessons I have learned. Perhaps the most important lesson is to seek and learn from mentors. Good mentors are sometimes tough to deal with. If they are really good, they challenge one's work just when one is getting happy with it. At the same time, good mentors tend to build two-way relationships with their students/colleagues. I always felt that my mentors and I were engaged in a common enterprise of building publicly shared understanding.

A second lesson from my early years, and also later on, is that accidents are opportunities. Whether it was several years without tenure at Pitt or being at Stanford instead of Michigan or having to work while a student at MSU, there were ways to grow presented by each accident. I report only the ones I was wise enough to respond to; I'm 
sure there were many other opportunities squandered.

Related to this is another lesson, which is that it is worth investing a lot of effort in the occasional adventure. I could easily have persuaded myself that I was not qualified to work for Prof. Wrigley. Instead, I took the chance, and that experience has shaped much of my career. On a number of occasions described below, I decided to be adventurous. One could argue that I simply exhibited excessive hubris. I think the difference between hubris and adventure is the extent to which one decides that doing something new will take a lot of hard work.

A third lesson really has two parts.

The first part is that scholarly success involves a huge investment of effort, whether it is work in junior high school or preparing a conference presentation or responding to editorial review of a journal article. For the scholarly world, though, there is another part to the lesson, which I have tried to pass on to my students. Scholarly success does not come from having brilliant ideas. Rather, it comes from being able to explain simply the ideas one has developed after extended effort. Developing those explanations, the art of scholarly writing, also requires huge effort. At least for me, the task keeps getting harder as I become more able to assess what I have written and to assess who will and who will not understand that writing.

\section{Research on Learning and on Reading}

I turn now to the work I have done since completing my doctorate. My work for the first ten years at Pitt was initially on the role of syntax and other structural constraints on what is learned from texts, on techniques for enhancing recall, and, near the end of that period, on the course of learning to read. In this work, I had some great colleagues. I did several years of work jointly with Charles Perfetti and also did a longitudinal study of reading acquisition with Lauren Resnick. Each line of work taught me important lessons.

In the work with Perfetti on comprehension of texts, I eventually realized that not everyone learns from texts the same way. Now, in this age of often unsupported claims of differing learning styles, that may not seem all that striking a conclusion. However, what I saw in our work was a bit different from current assertions about learning from pictures versus learning from texts. In a conference presentation for which I have lost the reference, I suggested a three-fold path to learning from text. Some people, I argued, have so much prior knowledge of the topic being addressed by a text that even if their reading ability is limited, they can figure out what is going on. Others primarily leverage incredibly facile ability to decode individual words and sentences and to keep their content in mind long enough to get connected to the content of the next sentences encountered. Still others have a repertoire of general comprehension tactics that allow them to make sense of texts even when they don't fully understand everything that is being discussed. Of course, really good readers leverage all three of these sources of reading capability, but different students often are weak on one or another of them.

This is important because it means that unified process models of reading that are purely sequential and that assume specific results from each element of the reading system will not easily be a good fit to all readers. For some, early stages will be incomplete in what they generate, while for others, the earliest stages of the process will drive the entire outcome. Prior knowledge may result in content being guessed by one reader while being extracted explicitly from text by another. There are no simple universal sequential process models of effective reading, though there are certainly normative patterns worthy of attention.

This lesson that not everything is simple came home to me in another way. When Lauren Resnick, Kathy Hammond, and I did our longitudinal study of the first four years of reading acquisition (Lesgold, Resnick, \& Hammond, 1985), we were interested in the relative efficacy of whole word versus phonics instruction. So, we 
developed structural equations models that allowed us to assess the extent of phonics instruction and the extent of whole word instruction and then to see which was a bigger driver of eventual reading success. The master plan was that we would follow some students in a reading program that emphasized phonics and others in one that emphasized the whole word approach and see which group made faster progress in learning to read. We did this, and we developed a structural equations model based on all of our data. It showed relatively similar contributions of the two approaches.

Given my long experience with the kinds of statistical ideas behind structural equations modeling (going back to my years of writing multivariate statistics programs with Frank Sim), I was worried about making strong claims about the results of such modeling without digging a lot deeper. I first built about 70 different models, testing each. I just wanted to be sure that some tiny change in the model wouldn't lead to very different conclusions. Then, I decided to model separately each of the two samples, the students given a lot of phonics and those given a lot of whole word preparation. I discovered that students who got heavy phonics had phonics as the primary determinant of their overall reading acquisition success, while students who got a whole-word approach had measures of whole word recognition as the main determinant of overall reading competence. Now, it could have been that both approaches work but that they teach different ways to read. That would have been consistent with the earlier idea of the three-fold path to reading success. However, it turned out that another hypothesis also explains the data really well. Students who get phonics training perform more consistently on phonics tasks, having become more practiced; there is less error variance in measures of their phonics skills. Students who get whole-word training become more reliable and consistent in whole word recognition; they end up with less variance in measures of whole word recognition. When a measure has higher "error" variance, it will have a lower correlation with other measures. In essence, it is entirely possible that some of what gets learned from either method is how to perform reliably on measures of the part skills being taught and thus to assure a higher correlation of those part skills with overall reading comprehension. ${ }^{2}$ The lesson to be learned is that it is dangerous to use any complex analytic approach without deeply understanding the underlying mathematics and without extensive testing to make sure that what initial analyses seem to be saying is really what is going on.

In working with students who struggled to learn to read, I noticed that while some faced special barriers, often they were, like the students studied by Sandy Dornbusch, ${ }^{3}$ not accurate in their perceptions that they were working harder than their peers. I ended up deciding that I could only understand what it was like to struggle in school if I undertook myself to learn something that was a struggle for me. Professors tend to come from among those who find school learning easy, so I needed to find something to learn for which I had no reservoir of skill on which to build. I chose oriental ink painting. I found a wonderful teacher, Louisa Yee, and had lessons from her at least once a month for three years.

I practiced painting, probably less than great painters but probably more often than it should take to become good. To emulate the ink-spreading characteristics of high quality Asian papers, I practiced on

\footnotetext{
2 Since then, some rather nice brain research data has shown the importance of phonics-type training (see, for example, Yoncheva, Wise, \& McCandliss, 2015).

${ }^{3}$ Dornbusch described his finding to me orally during that summer before I started graduate study. It was mentioned in a Stanford alumni magazine later on, but I have not found it stated completely explicitly, though it was part of Dornbusch's broader study of high school students (see Natriello \& Dornbusch, 1984, P. 56).
} 
rolls of the paper doctors spread on examining tables. It is cheap and unsized ink runs on it just as it does on high quality rice papers. At the end of the three years, I felt that I had learned nothing. I mentioned this to my wife, who then dug out all the pieces of paper on which I had practiced over three years and showed me that there was a clear progression toward better results. This was a shock to me, and even today I get emotional when I think about it. I learned an important lesson. People evaluate their capability with reference to competent performance that they see around them. It is easy for them to notice when they are substantially behind their skilled peers. It is much harder for them to notice the tiny incremental improvements that come each day with practice. Many years later, when thinking about a possible motivation research center in the school of education that I lead, this lesson helped shape my thinking about the scope of work the center should embody.

Another important experience occurred during those early years. In trying to understand how learning and memory processes might work, I became interested in the possibility of using artificial intelligence to build cognitive models. More broadly, I had become interested in the possibility that computer power could extend human power in theorizing. This led me in directions that eventually proved central to the best work of my career. Jim Greeno and I began more or less independently to explore some of the rulebased systems that were emerging as the field of artificial intelligence began to develop.

With the help of Harry Pople and Jack Myers, two Pitt colleagues, we arranged access to a specialized system that ran at Stanford on a computer that Joshua Lederberg and colleagues had acquired. At that time, in the late 70's and early 80 's, personal computers were not available and nothing small was anywhere near powerful enough to support rule-based systems. The SUMEX-AIM system that ran at Stanford primarily supported work there by Bruce Buchanan, Ted Shortliffe and others on MYCIN, a system for diagnosing infectious diseases. But, there was enough spare capacity that it could be used for other intelligent system and modeling efforts. The recently-developed ARPANET connected Carnegie Mellon University to Stanford, and Jim and I partnered with the Pople-Myers Internist project (an expert system for internal medicine diagnosis) to rent a highspeed telephone line from Pitt to CMU, which in turn connected to the ARPANET and thus to Stanford. ${ }^{4}$

If nothing else, this connection allowed me to teach myself enough about artificial intelligence to later do some useful work. I did a lot of modeling of the learning processes on which I was doing experimental work, although the models themselves did not rise initially to being worth publishing on their own. What became clear very quickly was that artificial intelligence tools would afford the opportunity for significant change in how learning and thinking were studied. There was another lesson learned through this involvement. From time to time, I would need one or another utility program (e.g., a sorting function) on the SUMEX-AIM system for my work. I would search for the utility on the system and access its documentation. Often, I found that the tools I needed had been written by Prof. Lederberg. Another lesson: great scientists make their own tools rather than being constrained by what is easily available.

By 1982, a few important things had happened that shaped a big chunk of my career as well as much of the field of

\footnotetext{
${ }^{4}$ There is an interesting tidbit in this story. Since Pitt did not yet have connections to the Arpanet/Internet, Jim and I were given accounts at CMU. However, eventually CMU decided to create the domain name of pitt.edu for the several of us from Pitt whom they hosted. With Jim's retirement and the unfortunate passing of Harry Pople and Jack Myers, I am pretty certain that I have the oldest email address at Pitt.
} 
cognitive science. At the time, the primary language for software that supported artificial intelligence was Lisp. But, most computers in general use had been built to support numerical computation. So, in laboratories at MIT and at the Xerox Palo Alto Research Center (PARC), people were working to develop specialized hardware to run Lisp (routine computer power was barely up to this task, so specialized hardware was necessary). The Learning Research and Development Center at Pitt had acquired a VAX computer in 1979 to support cognitive science work, but even that machine was barely up to handling serious machine intelligence. Eventually, both MIT and Xerox PARC developed Lisp machines, and it was clear that with this kind of tool, serious modeling of cognitive processes could now be done on a scale previously unimaginable. The machines were small enough to fit in someone's office and designed as personal machines (the smallest was the size of a two-drawer file cabinet). ${ }^{5}$

But, as some of us involved in this work reflected on the future, we saw a chicken-egg problem. To do the work that these new tools enabled, one had to get one of the new machines. But, there were many barriers to that happening. First, while Xerox PARC had invented potentially commercial versions of the Lisp machine, Xerox as a company really saw the platforms only as supporting office uses, not being specialized for artificial intelligence. Second, there was no maintenance infrastructure for the machines, and they had the kind of failure rate that required keeping technicians continually on call. Third, they were relatively costly, more than 20 times the cost today of a very high end desktop computer. That meant that researchers needed to be able to get grants to cover the costs. But, researchers didn't yet know all that much about the equipment, and funding agencies didn't yet have a basis for evaluating proposals. Fourth, there was need for considerable training before a cadre of researchers would be able to make serious use of the new tools.

The training problem began to be addressed via periodic training courses that Xerox and major AI centers would offer during summers. That still left the chickenegg issue of funding and infrastructure. So, somewhere around 1982, Henry Halff of the Office of Naval Research (ONR), John Seely Brown of Xerox PARC, and I had a brief chat in a hotel room while attending a research conference. This led to a plan to place the new Lisp machines in a number of laboratories around the country. Researchers in those places were selected based upon their recent publication and funding history. ONR provided the funding (from 1983 until 1990, when specialized machines were no longer necessary). Pitt provided the central home and an ONR-funded small support team that researchers could call when machines failed. Xerox PARC created a somewhat-informal ${ }^{6}$ arrangement that assured that components of the Lisp machines could be purchased if a part failed in one of the units. I remain extremely grateful for the flexible thinking and imaginative work that Drs. Halff and Brown provided to bootstrap the beginnings of a serious use of artificial intelligence tools in cognitive theorizing in the U.S. Shortly thereafter in the UK, Rank Xerox stimulated a similar deployment of Lisp machines in European labs.

There is another lesson here. All of the effort to stimulate the development of a cognitive science anchored in artificial intelligence efforts that could be empirically studied required a huge level of trust. Xerox was not focused on selling Lisp machines, so John Seely Brown had to be trusted to

\footnotetext{
${ }^{5}$ The Lisp machines did generate a lot of heat, though. Years later, on a cold winter day long after desktop computers were powerful enough for artificial intelligence work, I discovered that one of my colleagues had resurrected one of the machines to provide extra warmth in her office.

${ }^{6}$ Among other things, the supply chain involved literally a little old lady in San Jose whose TV repair shop always seemed to have the right components in stock.
} 
stay with the effort long enough to make it work. The Office of Naval Research had to trust that researchers who were given access to these machines would put in the time to master them and would use them to do better work than otherwise would have been possible. Both parties had to trust the Pitt group to be impartial and altruistic in their distribution and support of the Lisp machines. This was not that different from Milwaukeeans trusting that neighbors would put ashes on slippery ice patches in the winter or my parents trusting that someone would meet my plane in Oregon when I went to the summer NSF workshop. It is, though, quite different from the model of social goals that infects much of our political life today. It also is different from the much more conservative funding approach now favored in the federal government generally. End of sermon.

This early start in using artificial intelligence tools fueled my desire eventually to develop a technology of intelligent tutoring systems to teach complex problem solving, and of course it also accelerated the desire of my former classmate John Anderson and his colleagues to develop intelligent tutoring systems for teaching mathematics. But, in my case, some work on expertise intervened between this early start and my eventual development of intelligent coached apprenticeship systems.

\section{Research on Expertise}

Around 1980, there was quite a bit of work emerging on expertise, stimulated by the seminal work of Chase and Simon (1973). I was beginning to view reading as a form of expertise, and I was wondering if I could understand more about how to instill high levels of expertise by looking at some other domains. Bob Glaser and I discussed the question of what area of expertise to explore, and we decided to focus on an area that involved some level of perception, since perceptual expertise had not been explored much. We considered several topics, narrowed our choices to crystallography and radiology because of local expert availability, and ended up deciding to look into radiological expertise.

We did some very interesting work on radiology expertise (Lesgold, 1984), and some of it has continued to be cited as time passed. One of our findings taught me another lesson. We had focused some of our work on interpretation of very anomalous x-ray images. For example, we had a chest $\mathrm{x}$-ray of a person who had a lung lobe removed quite a bit earlier. Because the lungs behave a bit like balloons, when one lobe is removed, there is a considerable amount of unoccupied chest space that eventually becomes occupied as other components shift under pressure from expanding and contracting lobes that are still there. In the case I recall, all of the organs shifted around because of a missing upper right lobe, so everything was out of its usual place in this person, in addition to signs of the specific new disease process the person had. Images like this were difficult enough to allow us to see differences among three groups, first and second year residents, third and fourth year residents, and experts with over ten years of experience.

Because of the limited number of such films, we used them in multiple studies. Indeed, by accident we used a few with the same radiologists at both earlier and later stages of their residency training. We found that some images that were correctly diagnosed by early-stage residents were sometimes misdiagnosed by the same residents a year or two later, after they had acquired experience with thousands of additional images. Our seasoned experts did as well or better than the newer residents, so we spoke of a U-shaped learning curve that dipped at intermediate levels of expertise. We concocted a reasonable explanation for this phenomenon, namely, that residents gain, with experience, the ability to consider more possible causes for the body arrangements seen in an $\mathrm{x}$-ray image. However, when they first gain this ability to consider more alternatives, they have not yet become able to manage the memory load imposed by this deeper reasoning. To make a reasoned decision, they had to keep a 
difficult-to-perceive image in view and simultaneously consider multiple body arrangements that could produce that image (remember that $\mathrm{x}$-ray images are projections into two dimensions from three and that they show only the total density of a slice through the body, not all the edges of individual body components). That is, they had learned to think deeper, but they did not yet have enough of the deeper thinking capability automated to make it work reliably.

We made a lot of this U-shaped learning curve in at least one paper (Lesgold, 1984). Shortly thereafter, Dave $\mathrm{Klahr}$ sent me a note pointing out that Ushaped developmental curves were not all that uncommon in cognitive development and that perhaps I should become acquainted with the relevant developmental literature. He was right, of course, and that allowed this finding from a niche corner of psychology to be connected to a much wider range of better-understood phenomena in children. The lesson is simple. It really helps to be widely acquainted with the literature in a field. Getting overly focused can be helpful at times, since research is hard and presses against mental load limits. However, breadth of knowledge also is helpful in assuring that we end up with theories that are as simple and broad as possible rather than piles of unconnected fragmentary hypotheses.

\section{The Intelligent Systems Program}

All through the work on expertise, I kept in the back of my mind that I wanted to do more cognitive modeling and to leverage the tools of artificial intelligence more broadly in my research. One problem, though, was that the students attracted to graduate study in psychology seldom had the range of knowledge and experience to be able to acquire quickly the basics of artificial intelligence at the same time they were learning cognitive psychology. Discussions around the Pitt campus revealed that several colleagues in other disciplines who were interested in artificial intelligence faced similar difficulties finding students with adequate computational/formal/mathematical skills. Moreover, there were students already on campus in areas like computer science who really wanted to focus their doctoral work on a research problem related to artificial intelligence.

Initially, Harry Pople, a faculty member in the School of Business, worked with me to develop a preliminary plan for a doctoral program in artificial intelligence. Harry eventually left the University for a government-related job. So, Rich Thomason, a philosopher and computational linguist, and I developed the final proposal for Pitt's Intelligent Systems Program. There were students and faculty in the health sciences as well as in arts and sciences who were interested, so we designed the program to leverage faculty with appointments in existing departments who would do some of their teaching and doctoral advising in the intelligent systems program. This low-overhead approach has served quite well. The program was proposed during a period of leadership transition at Pitt, and that made getting started a little complex. However, with the support and advice of Tom Detre, the head of Pitt's health sciences, we were able to launch the program in 1986.

In many ways, Allen Newell at Carnegie Mellon University was the godfather for the program. We didn't always agree, but in the end, Allen convinced me of many things that I first saw differently. For example, my initial model was to hire a flock of assistant professors and see which ones we wanted to keep after a few years. Allen convinced me (during a meeting in his office that started at about $10 \mathrm{pm}$ one Sunday night and continued into Monday morning) that we needed a strong senior person more central to the computational side of artificial intelligence than me or Rich. So, Bruce Buchanan, who had been at Stanford in the SUMEX-AIM lab, was soon recruited as our first externally hired faculty member, and the program was launched. It remains to this day and continues to be anchored partly in computer science and 
partly in biomedical informatics, with additional participants in psychology, information science, education, and other units. $^{7}$ And, we now attract plenty of students with rigorous preparation in both artificial intelligence and another discipline. The lesson learned in this effort was that building a strong team makes a huge difference and that attending to the needs of the broader unit in which an enterprise will function really pays off.

\section{Developing Intelligent Tutors - Sherlock}

The work on radiological expertise, combined with thinking about cognitive task analysis that was triggered by my early artificial intelligence efforts, led to the next important accident in my career. Our radiological expertise work happened to be noticed by Dr. Sherrie Gott and her colleagues at the Air Force Human Resources Laboratory (AFHRL). The folks at AFHRL began to wonder whether training for Air Force technical jobs might be improved if those jobs were studied using the same methods we had used for radiology. At this time, the field of cognitive task analysis was developing quickly, and in essence the Air Force wanted LRDC to do task analyses of some technical jobs. Bob Glaser and I were pretty overbooked at the time, but we had a colleague who had a lot of talent but who was short on research funding, and we asked him if he would like to take on the project. He agreed and the project proceeded quite well. Bob and I contributed to some of it, too. However, when it came time to brief the general who was funding the work, it turned out that our colleague wasn't very good at preparing for or giving short, focused briefings.

I felt responsible for the project, having convinced the Air Force to fund it, so I stepped in, did the needed further analyses to support the tight briefing, gave it, and got us back into the good graces of AFHRL. Soon thereafter, Dr. Gott asked if
LRDC could do some further task analysis work and if Bob and I could lead it. By then, I was thinking hard about the possibility of intelligent tutoring systems, so I said I would join Bob in the work if I could also build an intelligent tutor for one of the job specialties we were to study. The Air Force agreed, so the seeds planted years earlier in the cognitive modeling efforts that used Joshua Lederberg's computer were about to germinate. There is a lesson here as well. On the one hand, we did what the Air Force wanted us to do. On the other hand, I also was able to persevere in what I most wanted to do - to build an intelligent tutoring system. It is worth working hard to deliver on promises to funders and also to stick with the problems that provide the challenges that keep us doing research. Initially, we analyzed two job roles, jet engine mechanics and avionics ${ }^{8}$ technicians. We learned some important lessons about mastery learning from these efforts. Using the standard instructional systems design procedures of the time (Branson et al., 1975; Gagné \& Briggs, 1974; van Merriënboer, 1997), training in the Air Force was developed by decomposing the target knowledge into small, coherent, teachable units, teaching each unit separately, and not moving to the next until a mastery test had been passed on the unit being taught.

We found, though, that these bitesized units could be learned fast but also could be forgotten fast. For example, even though all the technicians we interviewed for our task analysis work had "mastered" what a capacitor is, many, when asked later to describe the function of one in a circuit, said that they were fuses and could no longer recall what they had learned in the mastery curriculum. In daily work, capacitors only came to their attention when one burned out, so thinking they are fuses was a reasonable experience-based hypothesis, but it showed complete loss of

\footnotetext{
${ }^{7}$ As I write this, it appears that the intelligent systems program, the department of computer science, and the School of Information Science at Pitt soon will be more integrated.

8 Avionics is a term that refers to the electronics needed for aircraft navigation and operations.
} 
the earlier definition they had "mastered." Today, military training is assessed more often in terms of valued performances, though there remain vestiges in the training world of content briefly memorized, regurgitated, and then forgotten since it has never been used in real work contexts.

There is a lesson here for those who develop online educational systems. Quite often, those systems also divide the content to be taught into tiny pieces, teach each piece, test it immediately, and then decide that it has been mastered if an immediate and minimal-context test has been passed. Being able to define a concept or even to apply it in a very limited context does not tell us much about whether it is understood deeply enough to come to mind when relevant to new tasks that might present themselves.

While doing the task analysis work, I realized that in the information age, machines can do almost anything that we can teach using the old instructional systems design approach or its school-based variants. Humans, increasingly, are valued for their ability to apply old knowledge to emergent situations and to bridge between different bodies of knowledge resting on different ontologies. In schooling terms, life is an unfair test. Knowing something in the artificial context used when it is taught in school does not imply knowing it well enough to be able to use that knowledge in new situations. If we consider it unfair to test a student's knowledge using novel situations, we preclude knowing whether the knowledge that student acquired is usable or is "inert" (Whitehead, 1929). Realizing this led me to develop an intelligent tutor to prepare people for situations that were not explicitly presented as part of the training. In the terms of traditional experimental psychology, I wanted to do training for far transfer.

As luck would have it, while most of flight-line engine maintenance involved standard routines, with an emphasis on explicit protocols for testing and replacement of parts that would not function as specified, the avionics technicians struggled when encountering failures of the tools that allowed their dayto-day work to be routinized. These failures generally were novel or at least relatively novel. In years on the job, a technician was unlikely to see any given failure, though of course a few failures would occur and had to be handled. Still, given the low failure frequency, the limited training time, and the need to be prepared for whichever failures did occur, there was a clear need for training that produced "far transfer" in the sense that the specific circumstances in which the effects of training would be realized were not likely to be the situations on which training was provided.

So, we embarked on the

development of a system to train technicians not in their daily work but in handling of rare events for which they were not prepared explicitly. The domain of our work was the F-15 avionics test station. This was a tool used by technicians for the routine work of diagnosing and repairing electronic modules from the cockpit of F15 fighter planes. When a pilot reported a problem from a flight just completed, the technician would remove the module implicated by the problem report and carry out a series of routine tests. To do those tests, the suspect module was connected to the test station, which then was programmed via switch settings to carry out prescribed tests documented in a manual. That was the routine work, and there were tight procedures for that work to be regimented by the test stations and their programming. But, the test station itself could fail. There was no routine and no test station testers if that happened. Test station failures had to be diagnosed without routinized processes. They required explicit problem solving that had not specifically been practiced.

\footnotetext{
${ }^{9}$ In some of our work, we did even further far transfer studies, looking at the ability to repair failures of a different system than the one on which the training occurred.
} 
One can get a sense of the amount of experience arising in the field with test station failures from an interesting bit of data we accumulated in our work. We had reported that about 25 hours of training with our intelligent tutor produced as much learning as four years on the job, so I wondered how much experience with test station failures the average technician gets in four years. It turned out that the best estimate we could get was that technicians get perhaps 10-12 hours of experience diagnosing and repairing test stations in four years. So, we were preparing technicians for crucial roles that are exercised rarely but are crucial when needed, just as pilots practice in the simulator for events that probably will not occur during their working careers but that have high costs attached if they are not handled well.

We started our work with an idealized view of how training would occur. We thought we would have an expert model that could solve every problem, compare trainee performance to that model, and use the comparisons to develop appropriate hints if the technician was stuck. At the time, though, and to some extent today, systems simply weren't powerful enough to develop perfect diagnoses and perfectly tailored hints, nor was our pedagogical content knowledge complete enough for us to know exactly what knowledge gap was the immediate barrier when a trainee got stuck on a problem. This led us to an important conclusion, which is that when a trainee was sitting in front of our computer system, the smartest intelligence in the room was the trainee, even though we were trying to get them to learn something new.

So, our tutor operated by making relevant information available to technicians and then letting them select from several levels of hints. At one extreme, a trainee could simply ask to have their prior activity on the problem summarized and recapitulated. At the other extreme, they could be told exactly what to try next. In between, technicians could get pointed to the right general area of the system that they should be thinking about or get some help with approaching diagnosis in that area. In this training situation, where technicians are highly motivated to become experts to keep planes in the air and win wars, technicians did a good job of not asking for more help than they needed. Conceivably, in other applications, incentives would be needed to encourage students to invest cognitive effort and not just rely on the machine for guidance.

We learned an important lesson from our experience with hints. Over half of the time, when trainees asked for hints, they were able to proceed further after being given only a systematic listing of what steps they already had taken - with no new information. The work on mental load was just beginning at this point, but our experience certainly is consistent with a view that cognitive resources are limited and that sometimes lack of practice in doing complex thinking can limit one's ability to keep in mind all that is needed to do the required reasoning - even if one knows each element required to do that reasoning. Scaffolding often requires only a little bit of help. Had we developed perfect systems to search for trainee knowledge gaps, those systems probably would have provided too much scaffolding and have led to less transfer potential.

While many other things were learned from our intelligent tutoring systems work, they are documented elsewhere (Gott \& Lesgold, 2000; Lesgold, 2012; Lesgold \& Nahemow, 2001), so I present only a few details that may give a sense of how my career has been shaped by interesting opportunities and responses to those. One opportunity arose when we were designing displays to be available from the intelligent tutor. We wanted to have all relevant information available to trainees while they solved problems, and that meant storing gigantic schematic circuit diagrams in the system and providing an interface that could make any part of the diagrams available on demand. But, the whole diagram could not be displayed at once (because of limited screen space), so the question arose of what part to display when the technician wanted 
to consult the circuit diagrams. Initially, we fussed with all kinds of indexing systems, but eventually we came up with a basic design principle that I suspect has much wider applicability.

We decided that we would display only the part of the system schematics that an expert would probably want to see during the course of work on a diagnosis problem up to that moment. That wasn't all that difficult to determine. The expert model would have rules that would be triggered by the current problem state. Those rules referred to system elements. The system elements as well as the "goal stack" of higher level elements currently in focus, would allow us to present the "right" part of the display. But, that still left the question of how to make the display appear.

That turned out to be extremely simple. Our representations of the test station were hierarchical - they consisted of a few main system elements, which contained subelements, which contained subsubelements, etc. We used this hierarchical structure to drive the generation of displays in real time. For each system element or subelement, there was a simple routine that could display it. That routine would be told what part of the screen it could use, with elements that the expert model was focused on getting more of the display space. The element's display routine then would "instruct" its subelements to display themselves, telling each what proportion of the element's display space it was allowed to occupy. Display space was allocated as a function of how central a subelement was to the current "state of mind" of the expert model. If a subelement was allocated only a little space, it could not be further decomposed while generating the display. Overall, then, the display would show detail where the expert model was focused and collapse to a higher level of abstraction where the expert model was not focused. One of the team members was able to produce this whole scheme with less than 15 lines of code once we specified the circuit as a hierarchical object collection.
But, recall the design principle stated above that the smartest person in the room is the trainee. Because of that, we added a feature that clicking on any element of the displayed circuit diagram would open it up to display its subelements and their interconnections. So, if a trainee felt it important to check more details in the schematic diagrams than we had provided, he could just click once to see that detail. I have come to refer to this approach as intelligent shallow hypertext - the system displays what it thinks you want to see but makes it easy to see other things should it guess wrong.

As mentioned above, the approach I have taken in building the intelligent tutors was not to try to diagnose exactly what concept the technician was missing but rather to provide just enough cognitive support so that they could keep practicing and getting better at stretching their knowledge to handle new situations effectively, situations that were not explicitly studied. I believe that a modest caricature of the Common Core State Standards is that they have added to the curriculum more practice in applying what is taught to new situations, i.e., being able to stretch and broadly use what is being learned. If that is the case, then perhaps the approach we used has broader applicability. I should note that largely because of this distinction between deeply diagnostic intelligent tutoring systems and the kinds of systems colleagues and I developed, our second sponsor, Intel Corporation, insisted on referring to our systems as intelligent coached apprenticeship environments. They were probably right to do so.

I should comment briefly on how the initial Air Force system was named. Our later systems usually were just called ICA for intelligent coached apprenticeship, but the ones developed with Air Force support were called Sherlock. We were pushed by the Air Force to come up with a name for our system, and I'm just not much into names. So, I left the task to my colleagues, and one of them had worked with a pretty good artist. Between them, they came up with the 


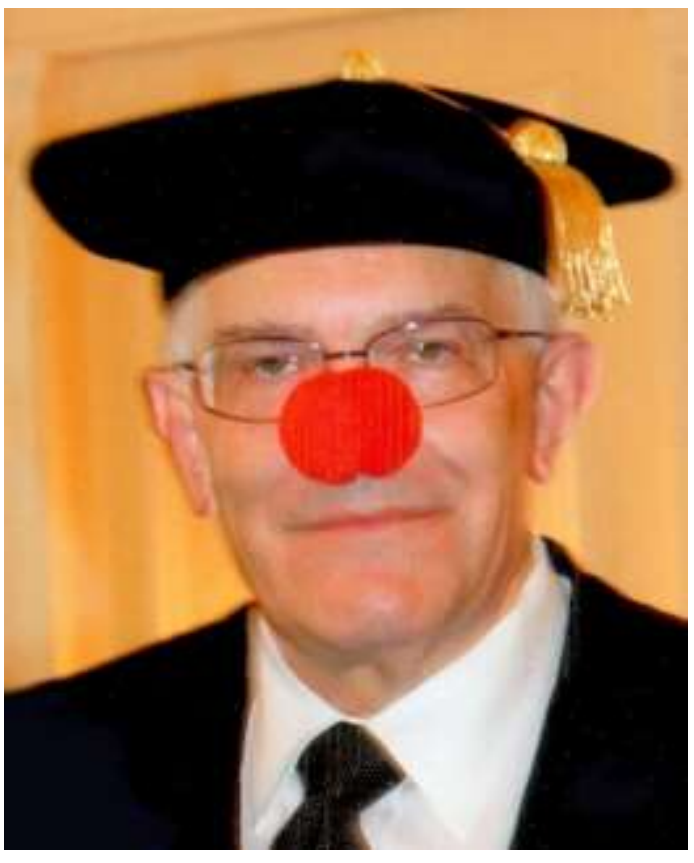

Sherlock name and related images. The reason the pictures of Sherlock we used displayed a pipe was to divert attention from a certain amount of within-project joking that the system was really the equivalent of Holmes" "7\% solution," the cocaine that he injected when he was really stumped by a case. This detail was one reflection of a broader principle that I pass on to graduates every year when I address them at graduation: take your work seriously, but remember that life goes better if you don't always take yourself too seriously (I then put a red ball on my nose prior to recessing from the platform).

We developed two generations of intelligent tutors with Air Force sponsorship. By the time we were done, we had a technology that worked well for the kinds of jobs that were major training problems for the Air Force. Moreover, we had demonstrated substantial far transfer as well as persistence of the acquired competence over extended time. However, we still were working in what I felt was too simple a domain. Test stations of the kind we focused on used old mechanical logic. Almost everything that happened in them was either directly observable (as the movement of mechanical elements) or at least easily envisioned even if it occurred inside a closed box. Moreover, the basic conceptual knowledge needed for any aspect of the diagnostic work either was already taught well in classrooms before technicians ever came on the job or else was in the realm of common sense reasoning. Even concepts such as the intelligent shallow hypertext displays might have worked only because the domain was so simple. So yes, Sherlock did provide in 25 hours the equivalent of four years of on-the-job training, but there are much harder cognitive tasks to be learned, so we had not really done such a good job demonstrating the power of intelligent coached apprenticeship.

The Air Force was interested in funding further work, but I decided that we could not afford to continue. The work increasingly was being funded by short-term contracts issued only when spare cash became available to one or another general. Contracting rules prevented us from charging any costs incurred before each contract was signed, but we needed to maintain a team of people who understood the work. We simply could no longer afford to cover the costs incurred when one shortterm contract ended and before the next one started. We could handle small amounts of that with the risky move of taking fixed price contracts (which meant that Pitt was on the hook if any piece of the work took longer than anticipated), working harder and faster than originally planned, and investing any "profit" in covering gaps until the next little contract appeared. That was not an adequate strategy in the end, and it also bumped up against lawyers who worried about whether the "profits" were taxable. At the time I decided not to take further Air Force funding, the Learning Research and Development Center at Pitt was spending about $\$ 150,000$ per year plus my own salary in sustaining the Sherlock work between contracts. The Air Force, at least at an institutional level, could not grasp this.

\section{The Intel Tutors}

Cutting the ties with the Air Force turned out to be a very positive move in the end. Shortly after we made the decision, Paul Chan at Intel contacted me to ask if we 
would be interested in teaming with Intel experts to further develop the intelligent coached apprenticeship concept. Because their interest was in maintenance of equipment used to make computer chips, which are much more complex than the test stations, this was very appealing. We could learn two things: whether we could make tutor development cheap enough to be financially viable and whether the approach could work for jobs involving much more complex technical knowledge. Throughout our Air Force work, AFHRL had an economist studying the financial viability of intelligent tutors for training. That person confused the likely unit cost once the technology was developed with the cost of inventing the technology and implementing it the first time - sort of as if people had written off light bulbs because Edison spent a lot of money figuring out how to make the first one.

There is a lesson to be learned here, too. The first version of Sherlock cost about $\$ 2.5$ million. This was the cost of a multiyear effort that invented the entire approach, implemented it for a specific job area, and evaluated whether or not the approach worked. We developed two versions of tutors with the Air Force and then three more versions with Intel. The cost of the final version was about $\$ 70,000$. Each generation cost less than half that of its predecessor. It is extremely unusual for any funding pattern to be sustained long enough to gain these levels of cost reduction. Generally, we rely on the market to turn research into a venture capital target. It is not surprising then that venture capitalists focus only on developing products that are either mundane applications of well-known understanding (e.g., almost all education start-up companies) or exploitation of an idea that has received strong verification and does not involve any novel production methodology (e.g., a new drug that can be sold at a high price to a large market). On occasion, it may be worthwhile for federal and other sources to fund multiple generations of refinement before hoping that the venture capital world will take over. ${ }^{10}$

All three generations of tutor development with Intel proceeded with the same basic organizational structure. We were set up like an Intel working group, and a representative of the plant management community was the project manager - that is, the project was led administratively by a customer for the system. Marty Nahemow and I were the intellectual leaders, and the project manager helped assure that we listened to both the experiences and the ideas of the potential users of the training systems being built. We are seeing many calls today for similar organizations in the preparation of teachers and even in research on how better to prepare teachers. This makes sense, but it takes effort to develop modes of operation that are comfortable for all participants and on the academic side we happened to have people who were amenable to the ego-free approach valued in the business world.

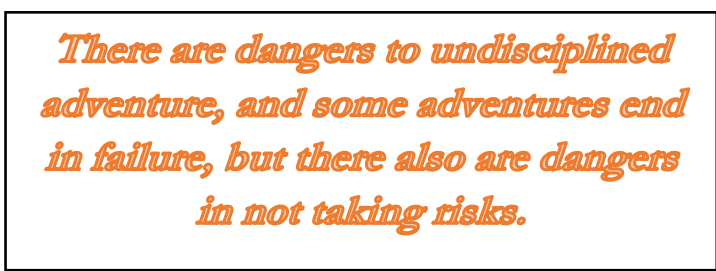

I also should say a little bit about my colleague in the Intel work, Marty Nahemow. Marty had been a manufacturing physicist at Westinghouse. As Westinghouse came on hard times, he decided to take a

\footnotetext{
${ }^{10}$ Of course, it could be argued that if I had chosen to move into business, I might have attracted enough venture funding to do the refinement that was accomplished through the five generations of research funding. Potentially, a funder could have been found, though going that route would have produced less understanding of what intelligent learning tools can accomplish, since market-related research is not quite the same as inquiry unbiased by financial motive. Also, current venture money for software tends to focus on applications where consumers are the market, not institutions, since institutional markets can always find a way to copy a product at lower cost. So, the market path really is not viable for intelligent tutors that will likely be sold to institutions (see Friend, 2015).
} 
retirement deal. Shortly thereafter, he joined us at LRDC and we embarked on a statefunded project to develop a high school curriculum that could be linked to apprenticeship in the machine tool industry. That work was a lot of fun. Unfortunately, most superintendents were deathly afraid of any programming that didn't aim at fouryear college, so only one district, Williamsport, adopted the approach we built. The project was, however, documented in Smithsonian Magazine in 1993 (Kiester, 1993).

Working with Marty was extremely rewarding. He is exceptionally smart. In fact, while at Westinghouse, he invented the screw-in fluorescent light bulb.

Westinghouse sold the patent to Philips for very little, but all of us have benefited from the invention in recent years. Marty knew a lot of physics, and he quickly picked up a lot of cognitive science. His presence at LRDC allowed me to take some chances that might otherwise have been a bit riskier.

This was true from the beginning of the relationship with Intel. One day, while I was still mourning the need to stop taking Air Force funding, I got a call from Paul Chan at Intel. He told me that Intel had determined that the first intelligent coached apprenticeship system they wanted to build with us would be one that taught technicians how to repair machines used to do ion deposition - putting layers onto computer chips. I agreed that we would like to collaborate in this effort as a way to refine and test our ideas about intelligent coached apprenticeship. But, I did not have a clue about what ion deposition was or what knowledge might be required to diagnose and repair ion deposition devices.

So, I walked over to Marty's office and told him that I had just agreed that LRDC would develop an intelligent coached apprenticeship system to teach diagnosis and repair of an ion deposition system and that I would love his help with this. Marty pulled his beard once or twice and then said that while his patents on ion deposition were for a different application, he thought he understood the process and would be able to provide expert advice as we built the intelligent training system. I breathed a sigh of relief and set out to learn from Marty. All in all, we did a pretty good job of building that first system, and it produced good results. We also cut the cost of development in half yet again, and of course we had moved from a domain with limited conceptual content (relay-based switching systems like the Air Force test stations) to one that involved a lot of physical chemistry, silicon chemistry, and physics. Note that the technicians we trained had perhaps two years of community college coursework past high school, so the extent of science content required to learn from our tutors was an important issue.

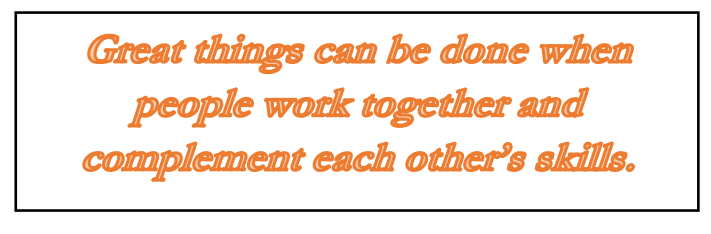

Given the success of the first project with Intel, I eventually got another call from Paul Chan. This time, he was interested in a training system for repairing ion beam implant devices, the devices that "write" circuits on layers in computer chips. Once again, I agreed to the project even though I had no clue about what ion beam implant processes were. Once again, Marty pulled his beard and indicated that his patents on ion beam implant were for a different application but that he thought he could handle the project. Once again, we built an extremely effective intelligent coached apprenticeship system (Lesgold \& Nahemow, 2001). Needless to say, I could not have done the work I did on intelligent coached learning environments without Marty.

The reader might assume that Marty only helped me with the physics. In fact, he absorbed a lot of cognitive science understanding and came up with an important element of our later tutoring systems, which we called the Process Explorer (Lesgold \& Nahemow, 2001). Recall that I mentioned above that the test stations were pretty simple. It was not necessary to learn a lot of new science to 
understand how they work. In contrast, chip making equipment leverages a lot of science, including silicon chemistry (a domain almost as complex as organic chemistry, except that it has to do with silicon rather than carbon compounds), quantum physics (involved in explaining where ions end up when they are "shot" at a chip), and other content not likely within the grasp of someone two years out of high school.

The Process Explorer was, in essence, a just-in-time delivery engine for little bits of conceptual knowledge that might help in understanding particular occurrences in the failure of chip making equipment. Many things can go wrong in such complex equipment, and the system failures manifest themselves in many different ways. Marty figured out how to handle just-in-time delivery of appropriate conceptual coaching. Consider a very large matrix, perhaps with hundreds of thousands of cells. The columns of this matrix are possible symptoms that might arise when diagnosing the failure of a chip-making machine. The rows are possible causes for those symptoms. Each cell of this gigantic matrix refers to how a given cause can produce a given symptom. What we put into the matrix cell was an explanation of that causal relationship. So, when a symptom was noted by a technician, he could get a brief explanation of each possible cause of that symptom. This was feasible because almost all of the cells of this gigantic matrix are in fact empty. To make relevant just-in-time explanations available to the trainee was a simple matter. The symptoms described in the data that framed the problem statement defined a small number of matrix columns, and the remaining columns need not be displayed. The relevant columns had entries in only a small number of rows, the rest were empty for the columns still active, so they also did not need to be displayed. For any given problem, therefore, there was a small matrix of symptoms and causes that could be extracted from the theoretically huge matrix.
Figure 1 shows an example of the process explorer in the middle of a problem solution by a trainee. What are shown in the columns of the matrix are the three measures for which the problem included indications of a deviation from normal. The rows indicate variables in the chip making process that could be responsible for deviations in those measures. The individual cells show whether the deviation that might have occurred would result in a small or large increase or decrease in the measure in question. Clicking on a cell gives an explanation of how such a change could be caused. In the example shown in the figure, the trainee has clicked on the cell showing that a substantial increase in stress on the chip wafer could be produced by an increase in RF power to the chip making machine. That click produced the explanation shown in the bottom right of the figure. Each explanation we offered consisted of a reduction of a complex phenomenon to a more or less linear relationship that could be explained readily.

The Process Explorer is another example of a recurrent experience in my career. What looked theoretically like a terribly complex and intractable task turned out to be quite manageable empirically. Yes, the machines in question depend upon all kinds of complicated science. However, the bits of that science that are relevant to the role being trained are relatively few and readily indexed. You could argue that it would be better if the trainees had complete courses in all of the relevant physics and chemistry. However, that is not practical. Doctoral candidates in those domains would not be happy spending their work days in bunny suits fixing the same small number of machines, nor could companies afford to pay salaries commensurate with years of graduate study. If we can deliver selfcontained and understandable chunks of domain knowledge that stretch a person's competence, that is a worthwhile thing to do, since it broadens their social value and earning capacity.

It is interesting that during the first years of my intelligent tutoring systems 


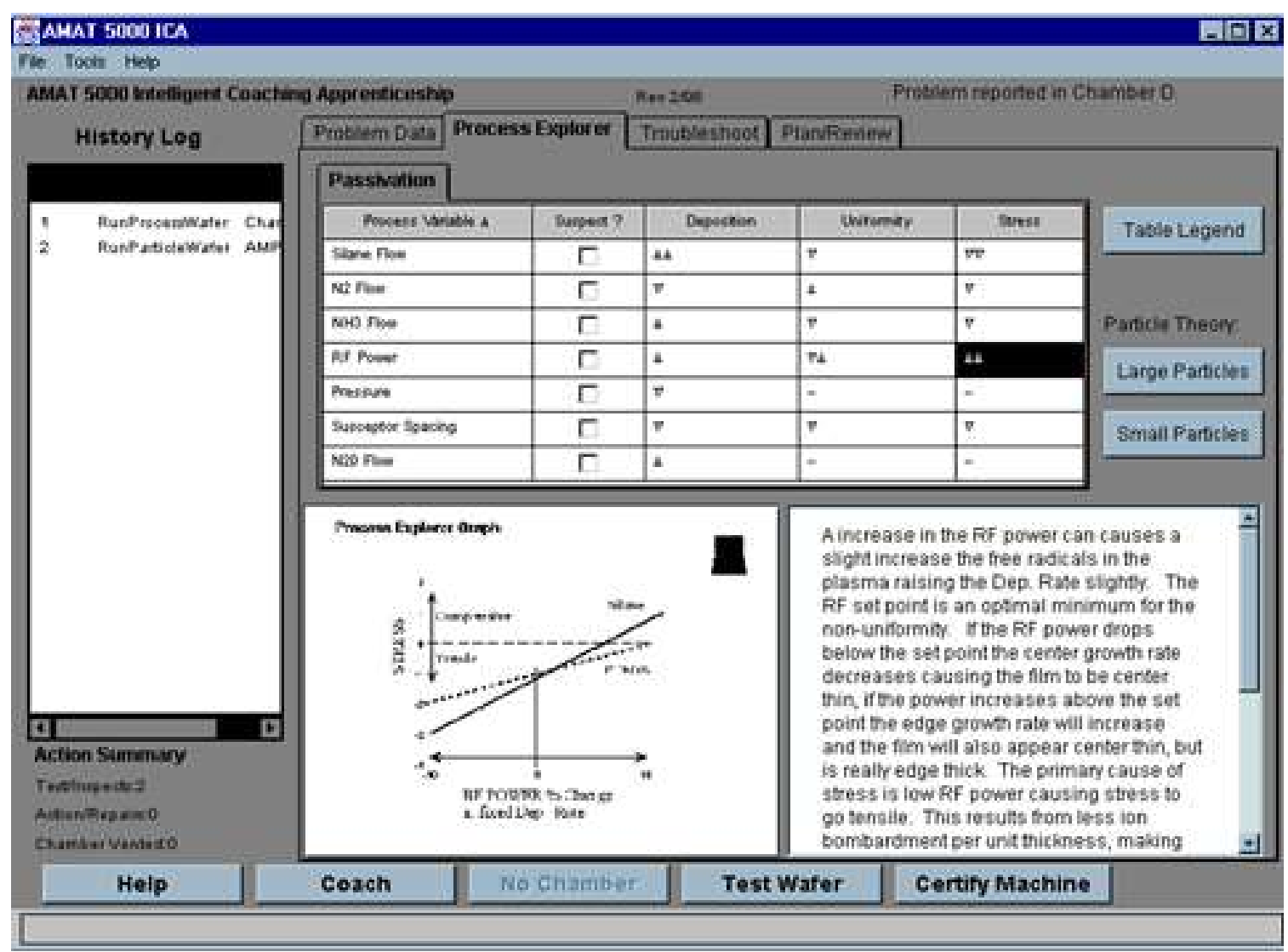

Figure 1. Example of Process Explorer.

work, a colleague in Computer Science worked hard to prove that building such systems was computationally impossible. He would have been correct if it had turned out that complete knowledge of each relevant domain needed to be part of the tutor's intelligence and that it needed to fully understand all of the thought processes a technician might be engaged in while solving one of the problems it posed. However, what was impossible in principle turned out to be quite possible in fact.

This lesson has had to be relearned many times since people argued that the Enigma code was not crackable by a computer (Stripp, 1993). In principle, reverse engineering the Enigma design was beyond the computational capability of computer devices of that time, which gave the German military confidence that it could not be cracked. However, Enigma was not used perfectly, and the actual ways in which it was used only partly tapped its potential. Cracking a perfect machine used imperfectly was a lot easier than the theoretical task of cracking the machine if it were reprogrammed as regularly as it could have been and if no mistakes had been made conveying the new Enigma configuration to all stations when that reprogramming occurred.

With our intelligent training system work, it was the limited relevance of large parts of the underlying science that made the task of just-in-time explanation tractable. And, of course, it took Marty Nahemow's brilliance both to discover that the process explorer was feasible and to manufacture simple and understandable explanations of many complicated phenomena.

The most satisfying part of the intelligent training system development work for me was the fifth generation. In that generation, Intel staff did almost all the system development, and again the cost was cut in half from Generation 4. We had shown that not only did our approach work, but it also could be realized outside the research laboratory. In fact, with an average 
savings of $\$ 80,000$ (due to shorter downtime) when one of the people we trained used their new knowledge for the first time, the entire cost of Generation 5 $(\$ 70,000)$ was recovered because of the reduced time that a manufacturing line was down and then restored by that trainee.

We had one other thing on our side as we proceeded, Moore's Law. It is quite possible that even five generations would not have been sufficient to produce a viable approach if computers were not getting faster during this period. From the beginnings of Sherlock to the last work with Intel, fifteen years elapsed. Given Moore's Law, we can estimate that the amount of computer power available for a given price doubled ten times over that period, giving us, for the same level of investment, over 1000 times the capability at the end of that period compared to the beginning. Had it not been for the industrial realities captured by Moore's Law, that computer scientist who was proving that my goal was impossible to attain might have turned out to be right, at least temporarily. The lesson to be learned is that sometimes it is sensible to aim beyond what is possible today, provided that there is reason to believe that needed elements for solving a problem will become available faster than the thinking needed to deploy those elements. So, either I was visionary or I was slow enough that the world moved faster and became able to adapt to the limits of my thinking. Either account matches the data.

Quite a number of students, programmers, and post-docs worked on the intelligent coached apprenticeship environments we developed, and I learned from all of them, including Sandra Katz and Susanne Lajoie, both of whom have developed strong research careers. There is another lesson learned about which I have written before (Lesgold, 2012). The fact that we had developed and refined a practical and powerful new learning approach did not mean that it would instantly be deployed. In fact, no one has fully used the technology we developed beyond the specific efforts in our five generations of work, although partial uses are becoming more common of late. While the work has influenced some of the recent increase in use of intelligent tutoring systems methodology, its influence has been slow and applied only partially. To understand why this could happen, even when the cost of deployment can be recovered when one person uses the knowledge the system teaches, it is useful to look at the medical world for a moment.

Medicine has a long tradition of basic and applied research, and the national investment in both has been huge. Still, it is not unusual that well-established applied results do not automatically lead to changes in practice. Procedures for avoiding hospital-induced infections are a simple example. We know that certain infections often are transmitted in hospital settings. We also know that the chances of transmittal are decreased markedly when hospital staff wash hands before and after seeing each patient. Nonetheless, those findings, by themselves, did not sufficiently influence hospital practice for quite a while. Even today, infection reduction is a work in progress, but it is now clear that a variety of specific institutional interventions are needed for it to occur, including placing needed equipment and supplies right at hand in front of each patient room, counseling patients to remind staff to wash and glove, and providing financial incentives to hospitals for reducing infection rates.

The research needed to get human systems ready to use accumulated applied research is called translational research. In medicine, major centers have been established to conduct such research, and it is starting to pay off. In education, such efforts have been started, but really good translational research is still rare. For example, the Institute of Education Sciences has a category of research support which they have called "Goal 4." It is for efforts to take an applied result that is well grounded in past research and to show how to get school systems to improve their outcomes using that research. Very few submissions have come in for that funding category, and extremely few proposals have 
reached the quality level needed for funding. Certainly, in my work on intelligent tutoring systems, it became clear that real payoff would require substantial translational efforts. Possibly, as machine intelligence is better absorbed into our culture, the gap between the work we did and wider adoption will be closed.

\section{Tools for School Learning}

After the work on intelligent tutoring systems, I did a bit of work on tools to support argumentation. I was influenced in this work by a number of factors. First, it was clear from research of others (cf. Sieg, 2007) that intelligently coached graphical environments might be very useful in helping students learn to develop arguments more completely and to collaborate in doing so. This led to a project focused both on developing graphical tools to represent arguments and on building coaching systems that could "observe" students collaborating to build such a graphical representation and coach their collaborative efforts (Suthers et al., 2001; Tothet al., 2002). The basic goal was to build a system that allowed students to represent an argument graphically. For example, when we gave a couple students a text about the possible causes of the demise of dinosaurs, a piece of the argument diagram they developed is shown in Figure 2. The figure shows only the very beginning of a discussion by the students, with the arguments being developed represented graphically in the diagram. The diagram allowed them to indicate hypotheses, data, and relationships of knowledge elements to one another. We called the system

Belvedere, since it graphically displayed an overview (the translation from Italian of belvedere is overview) of a developing argument.

The overall system was rather interesting. It included a representation of the specific pieces of knowledge added by students, the overall accumulated diagram, and an intelligent coach that tracked the ongoing development of the argument diagram. The coach "observed" the pattern of student contributions and provided advice based upon that pattern.

Figure 2. From Suthers et al., 2011.

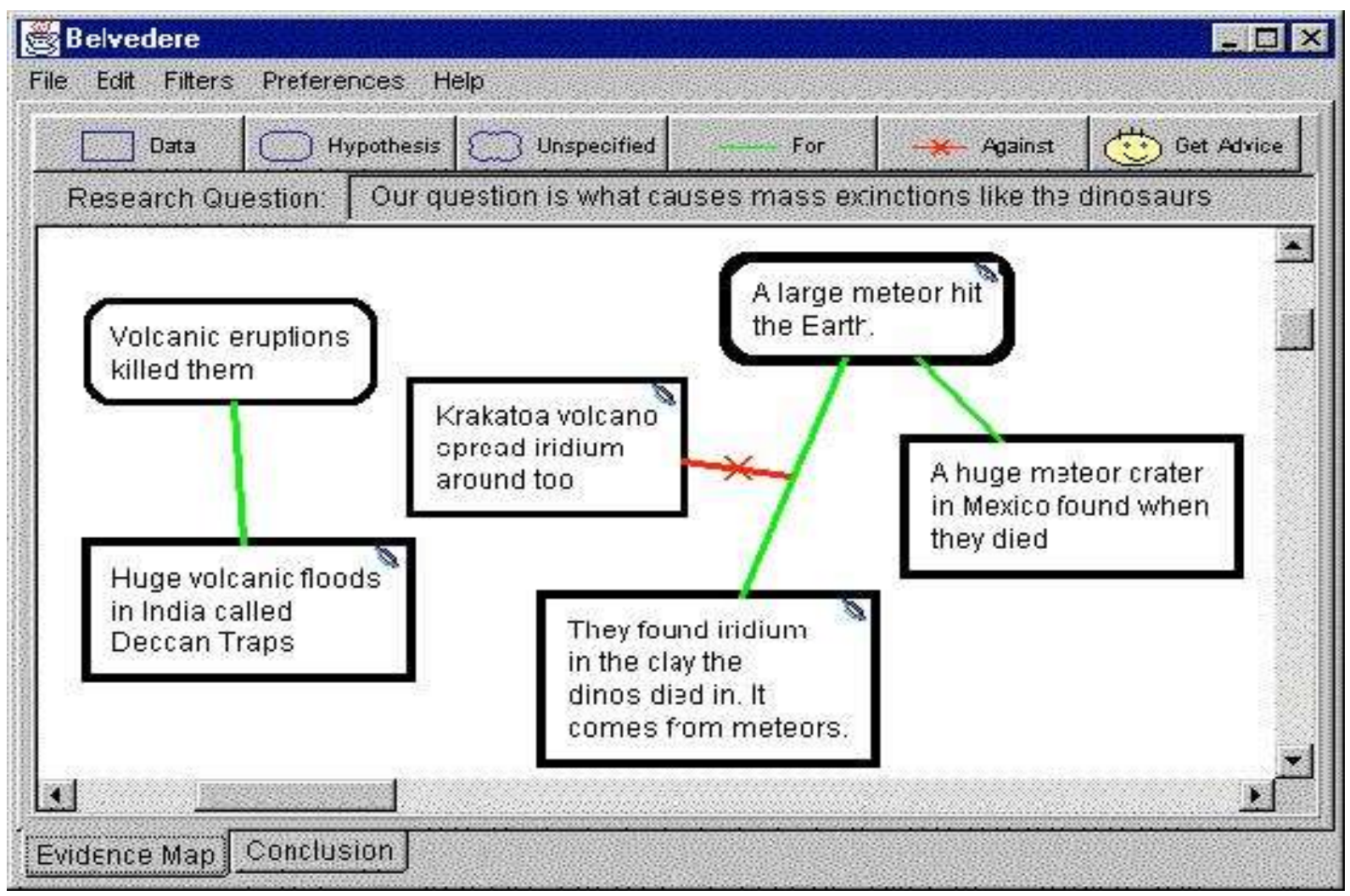




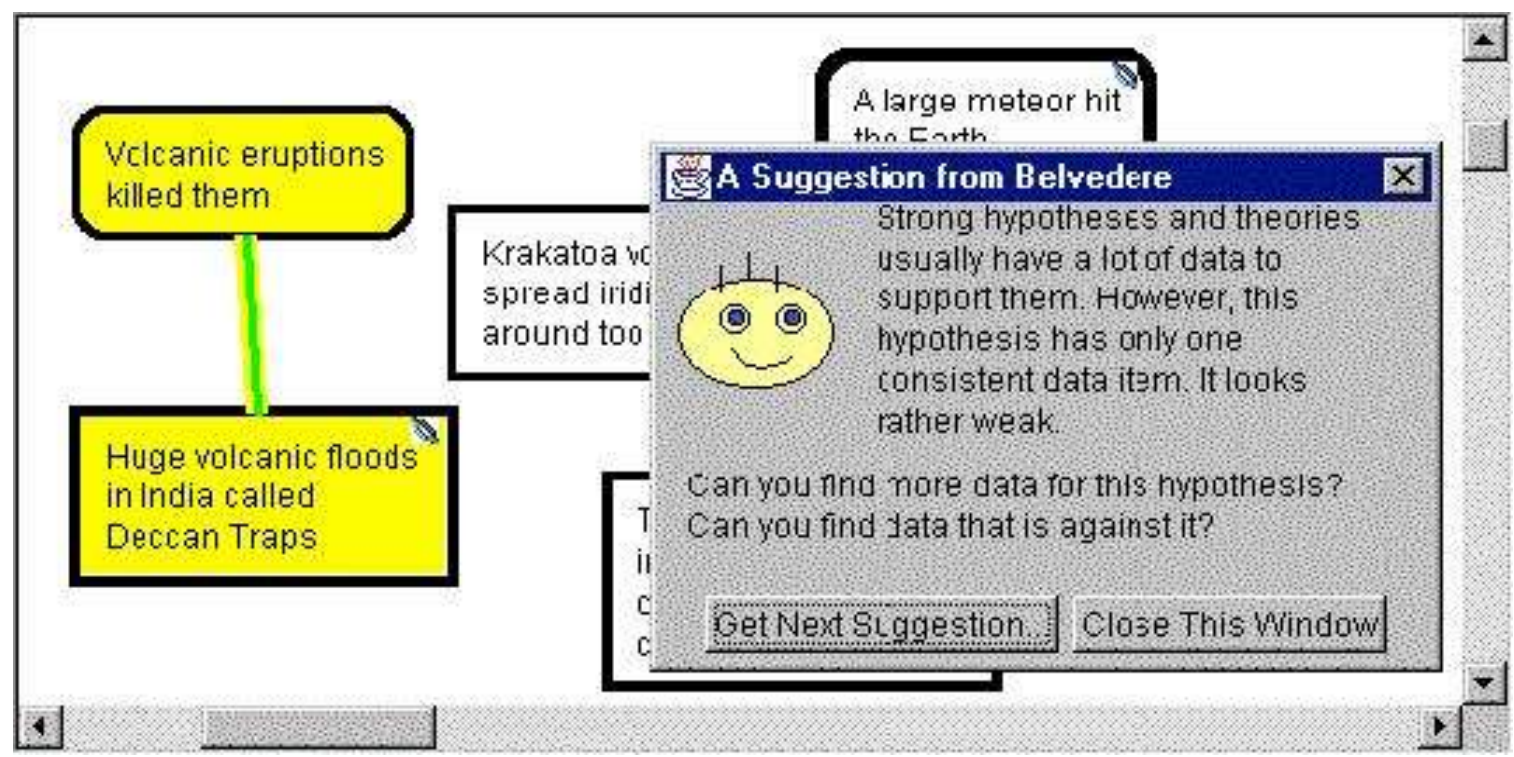

shows an example of the advice that could be offered at the point where the diagram had progressed to the state shown in Figure 3.

The system had some interesting computational characteristics. For example, the coach ran on a different computer than the argument display environment, observing the stream of student activity and generating suggestions based upon how the activity progressed. This was done for multiple reasons. It had the effect of allowing the coaching system to run on a more powerful computer while the diagramming system could run in multiple low-cost student computers. This reflected our belief that we could not predict the kinds of computers that might be used in schools for different purposes, except that networking would get easier and computer power would get cheaper. It also meant that arguments could be developed by groups of students distributed geographically while having a coach in a central machine. In a sense, we anticipated architectures like Google Voice that are partly in a small computer (e.g., a phone) and partly in the "cloud." In moments of extended optimism, I imagined students in different countries developing arguments about international affairs with neutral coaching from the cloud based upon the structure of
Figure 3. From Suthers et al., 2011.

those arguments. This was optimistic for multiple reasons, including the likelihood that an argument's adequacy may depend upon meanings of terms that might not be shared cross-culturally. Still, systems like this could be quite powerful.

Certain members of the team involved with the Belvedere effort have continued to do related work independently, including Dan Suthers, Patrick Jermann, and Amy Soller. It was a real blessing to work with them. I suspect that the approach that we took could generalize to good effect. Schooling historically has involved students working independently on structured assignments. But, schooling in the future will include more student project activity where less of the specific knowledge being engaged by a student will be predictable, students may work in groups, and aspects of the structure and perhaps the content of their work will be represented using various tools. Perhaps it will be useful to work toward intelligent systems that can keep an eye on student work and occasionally comment in productive ways even if the details of what students might be thinking or might be trying to do are not always evident. 


\section{Preparing Educators}

While my career has taken a number of turns over the years (several such turns are omitted from this account, though they contributed ideas that later influenced my work), there has been a continuing theme throughout. I wanted to learn how to make more learning happen when it matters. Sometimes, that meant figuring out what it meant to be an expert, and sometimes it meant figuring out how to support the practice that leads to expertise. Believing in the importance of research to improve education, I was continually forced to realize that finding out important things about learning didn't necessarily mean that better teaching would occur, or that students would learn more. My early immersion in medical expertise prompted many reflections over the years on how the teaching of medicine has progressed compared to the teaching of teachers and their students in pre-college education. Eventually, I came to believe that if I kept on doing the kind of work I had done, it might not have any lasting impact on schooling or training, even though what I was learning was highly relevant to educational improvement.

Concretely, this was manifest in my university in a disjunction between LRDC, where I had pursued my career, and the School of Education, which I felt was not teaching some of the most important concepts that came out of work by my LRDC colleagues. This was not an issue unique to Pitt. ${ }^{11}$ There were many good to great schools of education that were not translating certain major findings of basic and applied researchers into tested approaches to school-based practice. Eventually, I came to feel that it would be better to work on this problem than simply to complain about it. I flirted with one or two other possibilities but could not bring myself to leave the University of Pittsburgh, which had supported my efforts even when
1 brieff aside. Two years after I became dean, I also became, for 30 months, the president of a large Reform Jewish congregation. I learned a lot from that experience, including that a room can be too hot and too cold, services can be too short and too long, and liturgy can be too traditional and too contemporary, all at once. I served during a rough moment for the congregation, and it taught me that one can come through rough times with the help of friends and that one's opponents often are well meaning but that organizations still need to choose among conflicting paths that all have justification.

I remain indebted to those who kept me going on some really dark days, and I deeply respect those who disagreed with the directions I took. Much as I learned, though, I do not recommend holding two jobs requiring pastoral work at the same time. Both roles do have in common the reality that if you do them long enough, you have to deal with some extremely self-destructive behaviors.

they stretched the boundaries and goals of individual units to which I was appointed (LRDC, Psychology, and Intelligent Systems). When the deanship opened in Pitt's School of Education, I decided to be a candidate for it.

Many people wondered if I knew what I was doing, including the Chancellor and the Provost. They came to realize that I was fully aware of the costs of being a dean (I really wasn't, but I was as close as anyone is who has never had the job), and I was fortunate to be appointed dean in July, 2000. It has been a wonderful experience. It has been a privilege to help such a fine group of colleagues achieve great things.

In the course of my deanship, I realized that simply bringing the kind of

\footnotetext{
${ }^{11}$ The Deans for Impact group recently produced an account of the principles of learning that it believes all prospective teachers should master. It can be downloaded from http://deansforimpact.org/pdfs/The_Science_of_Learning.pdf
} 
cognitive science that LRDC excelled in to the School of Education was not enough. Pitt has always been a stronghold of the best in subject-specific pedagogy. While teacher preparation in many schools of education then, and in quite a few even now, included generic teaching methods courses and weak subject-area majors, we at Pitt always had subject-specific teacher preparation and also required a full undergraduate major as a pre-requisite. To become a math teacher at Pitt, for example, one not only has to have a bachelor's degree in mathematics, one also takes methods courses specific to the teaching of the various hard topics in math, such as rational numbers. Those courses are taught by education faculty, many of whom can and sometimes do also teach in disciplinary departments. I still believe that this is extremely important. Different subjects have what Lee Schulman (2005) has called different signature pedagogies. One does not teach writing the way one teaches mathematics (though there are common elements in coaching learning-by-doing in the two subjects).

Being dean of a school of education, though, forced me to spend more time looking at schools and schooling. I came to feel that the subject-specific pedagogy work at which Pitt excelled was improving the education of privileged children substantially but was not working for many children whose families were less wealthy, including many children of color. To benefit from all we know about pedagogy, students need to be immersed in the learning opportunities that teachers engineer. That means they need to come to school, engage the learning situations available there, and persist in tasks that are presented to them.

This sounds simple, but it is not. When I went to school, the community from which the students and the teachers came was quite homogeneous. Students were all from a white community, were all from families of roughly the same wealth (middle and working class), and were taught by teachers from similar backgrounds.
Everything outside of school supported everything that went on inside. This included a pervasive social belief both in the American dream that one can advance one's circumstances by working hard and in the major role of education in supporting that advance. Those around us who had been successful in life routinely conveyed the message that working hard in school was important to their success. And, of especial importance, there were plenty of good jobs for people who had worked hard in school, learned to show up on time, and learned to follow directions, even if their overall performance on tests was less than stellar. Today, this is not the case. The schools around me in Pittsburgh, like schools in most cities and rural areas, serve a wide range of students. Some come from impoverished families while others may come from better circumstances. Those well off generally go to different schools than those who are poor, though all are taught by teachers from the middle class. Students of color often are taught by white teachers whose lives are dramatically different. There are several important differences between urban public schools today compared to when I attended one in the middle of the $20^{\text {th }}$ century. First, many students have no experience with adults who succeeded in life because they did well in school. In addition to multigenerational damage from inadequate schooling, other factors including race have created a situation in which some communities, based accurately on their experiences, do not share a common belief that schooling is important to success in life. In addition, while white children from wealthy families spend their days in bright, cheery school environments, many children of color experience schools that signal that society does not care about them except to keep their behavior from causing problems. Finally, many schools, especially those struggling in low-income areas, do not provide education in key knowledge and skill requirements for the information age.

It would be easy to decide that all that needs to be added to what worked in 
my generation is social justice, but that will not be sufficient. For one thing, giving every child exactly what I got no longer is enough. Machines do most of the things that average and below-average students learned to do in the schools I attended, even though our society has yet to adapt to this fully. So, part of the problem is that children not well served by schooling are making decisions to disengage that are grounded in assumptions that are at least partly true. Any effort to change this must include a focus both on justice and on aiming high enough in our educational goals. In addition, regardless of how enticing we might be able to make schooling, it also is likely that the total effort required of today's students if they are to have good lives is higher than was needed for my generation.

This calls, I believe, for a multipronged strategy. First, we need to do a lot of research on motivation, persistence, and engagement. Regardless of what else happens and even if schooling becomes perfectly fair tomorrow, we have generations of families who have learned about schooling from experience, and what they have learned may not be optimal for assuring community support for student success. We need to understand how to get students more engaged and how to induce them to persist in the work of learning. Second, we need to document and clearly explicate the differences between schools for the privileged and schools for the underprivileged. While selfishness, as embodied in suburban flight and other forces that make education separate and unequal, will not disappear, the effects can be ameliorated if more of the voting public understands how bad the situation is and how it might change. And, less privileged families need to understand what it takes for schooling to make a difference in their children's lives. Parents need to be pushing for schools that prepare their children for good lives, which may require more than assuring the delivery of diplomas that may not be coupled with deep preparation to use school-taught knowledge to solve novel problems. Some of that preparation should include practice in collaborating with very different people than a student may be used to, for example, and parents need to learn why that could be important.

Third, we need to help students learn to lead healthy, active lives. For a while now, recess and physical education has been sacrificed in many schools, often to allow just a little bit more drill to prepare for standardized tests that capture only part of what our children need to learn. We know that students who are more fit physically achieve more in school (Donnelly \& Lambourne, 2011; Van Dusen, Kelder et al., 2011). We also know that personal behavior decisions impact both health and the cost of health care. Part of schooling needs to be about helping children learn to live healthy lives.

These three areas - motivation, education for the less privileged, and education in healthy living - have been a focus of my tenure as a dean. I have had the good fortune to be surrounded by great colleagues who are making impressive progress on these foci. I saw my role as supporting their efforts and helping assure that they were eventually joined by even more talented peers. This part of being a dean I feel pretty comfortable about. We have remained strong in subject-specific pedagogy, and Pitt overall has remained a major force in the cognitive science of learning, but in addition, we also are focused on these three important areas.

I am just starting to understand what schools of education should be doing in different areas. Schooling as we know it today was dramatically influenced by the industrial age. Sometimes, this influence is associated solely with extreme prescriptions of the sort advocated for industrial jobs by Frederick Taylor (1911). Taylor saw much of human labor as inefficient, and he pioneered time studies of work that could lead to more production per worker. A benign example of this is the specification of delivery routes for UPS drivers that eliminate left turns, which take a lot of time because oncoming traffic has precedence over the person turning. A less desirable 
result was redesign of assembly line jobs so that workers kept repeating a small number of movements and thus could grind out a few more widgets each hour.

Unfortunately, much of the Taylor approach in education has focused on scripting teacher performance to eliminate variation that was seen as inefficient.

Sometimes, such scripting resulted in small increases in test scores, but it also interfered with making major changes in goals and processes of schooling needed for the information age. And, as in factories, it demoralized the workers, in this case both teachers and students.

Even when teachers have been given a lot of freedom, the world of education has been organized like a corporate bureaucracy. In addition to the bureaucracy of school systems, additional layers of bureaucracy exist at the state and federal level as well. At a minimum, very simple accountability measures have been used to assess how well school systems, schools, and teachers are performing. Instead of money, which is the accountability measure of the business world, education uses standardized tests.

A simple accountability measure has strengths and weaknesses. The focus on profits has worked well for shareholders, but it has not always served social purposes nor has it assured the long-term health of businesses. After all, sometimes shareholders profit most when a company is stripped of its assets, even if workers are left in the lurch. Also, customers are not always helped by such measures - anyone who has taken a plane trip in recent years understands that airline profits do not map onto customer comfort. All in all, our economy works better because we attend to profits, but it could serve society better still if we had additional measures of corporate contribution.

The currency of test scores has worked similarly. Overall, test scores tend primarily to predict initial success in college, generally the freshman year, when grades come largely from mass testing similar in form to the tests used to measure school success. To the extent that achievement tests correlate highly with aptitude tests, standardized tests also predict, to some extent, the quality of life in one's later years (Holahan \& Sears, 1995). At the same time, there are a variety of pathologies introduced when schools focus solely on boosting mean test scores. Deep engagement of content is sacrificed to drill. Teachers focus on students in the "bubble" who can, with minor gains, advance from one score category to another (e.g., from basic to proficient), ignoring the students who need the most substantial help. Socialization in kindergarten is sacrificed to have time for drill on accurately filling in multiple choice test forms. Art, music, and physical education, which are not tied to test score improvement in the bureaucratic mind, are

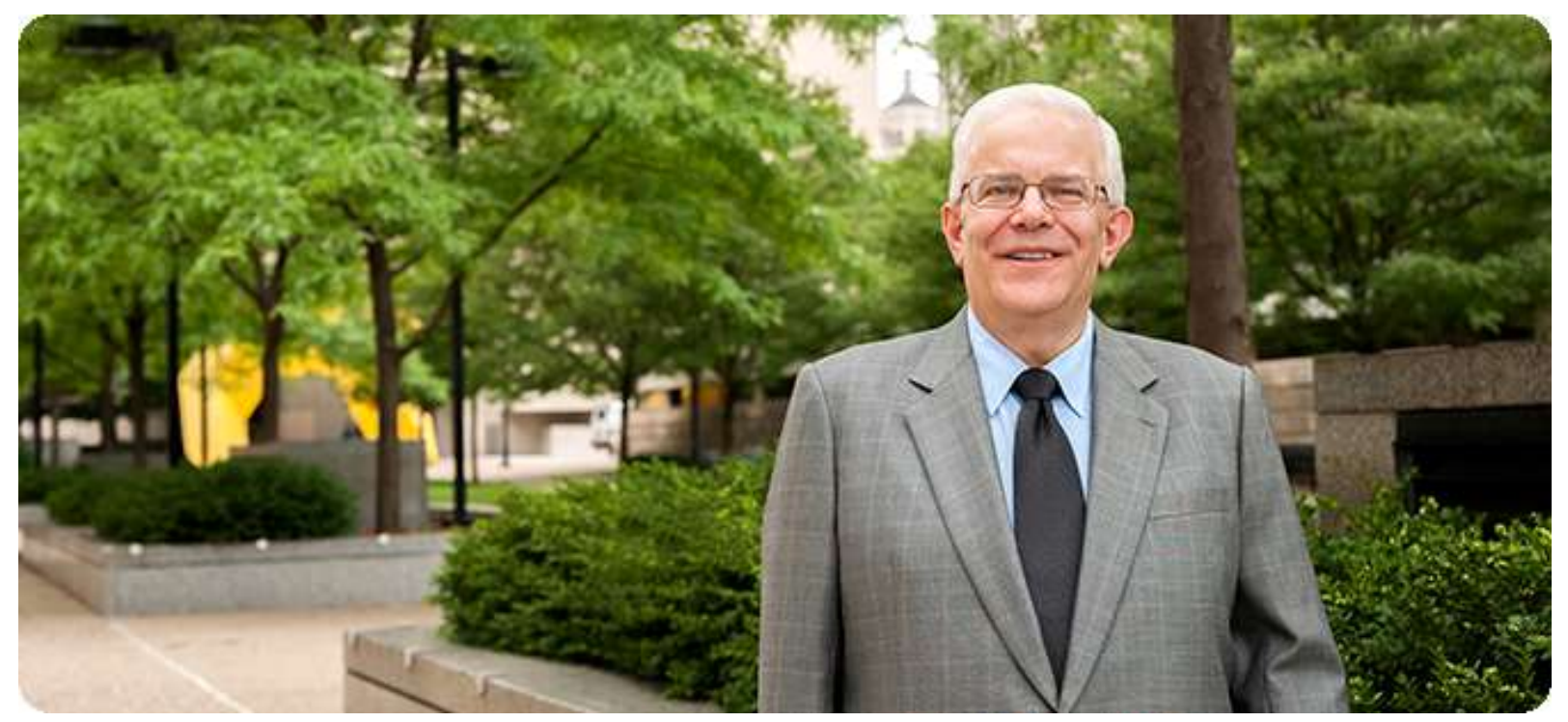


sacrificed to make room for a few more minutes per day of drill. Students disengage and drop out because classroom life is so regimented that it parallels the soulless life of assembly line workers at the height of the "scientific management" era.

Society is demanding that we change this, though policy makers struggle to figure out how the change can happen. Parents revolt against testing when their real concern is about the depressing nature of some classrooms. Moreover, in addition to demand for change, we also see flight from regimented, test-driven schooling. Children of the wealthy may get paid tutors who help them to do better on the SAT, but the schools they attend throughout childhood are not driven by standardized test scores. Instead, students get large projects to work on that afford opportunities to practice the $21^{\text {st }}$ century skills linked to creativity, collaboration, communication, and using old knowledge to attack novel problems. They give up large chunks of class time to rehearsals for the annual school play or musical. They also write more even if competent writing is not captured very well by multiple choice tests.

Those of us who prepare educators should, I believe, be working to bring the schooling that serves the wealthy into universal public use. To do this, we need to do two very big things. First, we need to prepare teachers, principals, superintendents, and policy makers to work in school environments that are healthy and that provide students with multiple, meaty patterns of activity as they develop their knowledge and competence for life in our increasingly automated world. Students need to learn how to work in teams on complex problems for which no one person is fully prepared. They need to learn how to learn new skills quickly, since any job will eventually be a candidate for automation.
Rather than getting all their practice on small performances for which they are deeply drilled, they need to practice confronting tasks that might not have been imagined even a few years ago and at investing effort even when there is some chance of failure. This is a matter both of specific skills - managing student projects, stimulating "maker" activity, ${ }^{12}$ etc. - and deep understanding of how the rise of machine intelligence is changing what makes people valuable to their neighbors.

Second, we need to develop alternative ways of assessing how well learning is proceeding. For starters, just as foods in the store and increasingly even in restaurants contain nutritional labeling, we need to develop simple schemes for labeling the educational nutrition value of games, apps, projects, cyber school lessons, and other learning opportunities. My father ate his meals during army service in a mess that was regimented like the factories of that time. An expert figured out what should be eaten each day, and everyone got the same thing. Today, parents make choices for their children, sometimes guided by nutritional information that food products must provide. The schools of the future, in order to rehearse for life in the future, will need to be places where teachers and students choose from a range of possible activities, guided by indices of their "nutritional" value, and also get periodic assessments of their learning health just as we get physical examinations and feedback on our physical health. We will, of course, need to help parents and teachers learn to use education's equivalent of nutritional information, and we will need to learn how to assess the "nutritional" content of activities for the mind.

As noted above, much of this scenario exists for the wealthy, though the measures are mostly personal intuitions

\footnotetext{
${ }^{12}$ In recent years, some schools have put aside time for students to make artifacts that interest them. Making a complex object or computer application requires practicing the skills mentioned above: creativity, collaboration, communication, and applying old knowledge to novel situations. The trend toward this kind of activity in schools and in after-school settings has been referred to as the "maker" movement.
} 
enforced by the power of personal wealth. The wealthy would benefit from the assessment approach just suggested. The less wealthy would benefit not only from such assessments but also from well-trained, imaginative teachers taught to proceed fearlessly in making learning opportunities for their students.

We have, in recent years, seen a great deal of deconstruction of our public education system. Without efforts by the educational research and teaching community, this likely will continue. And, it will work for many children, but not for all. Parents who received a strong education and who are adapted to the information age will be able to curate the learning opportunities available to their children, and those children will be served well. But, not all children have the benefit of parents with a solid education along with family resources sufficient to support access to many learning opportunities. Those children face a very real probability of not being prepared to fare well in an individualistic world where the ability to do more than cheap software can do is the key to economic success. The number of such children already is high, because we have failed many children for over a generation and they now are parents.

With increased economic division between great wealth and bare subsistence poverty, the effects of past failings of our education system likely will grow and certainly won't decrease. And, more routine jobs are disappearing because of automation, along with jobs requiring only a modicum of intelligence. The education schools of the future will need to attack this problem in diverse ways. Some will try to recreate universal public education. Some will try to assure that an open marketplace of educational options is partly disciplined by improved ability to assess the likely utility of various offerings. Some may even develop their own offerings in the cyber world. The stakes are high. If we don't attack these fundamental issues, our value for society as educators will diminish, and education schools as we know them may disappear.

I believe that among the educational opportunities that should exist in the future are systems like the intelligent tutors that I built. Those tutors allowed technicians to take knowledge acquired earlier and apply it to really tough problems, thus learning how to make use of what they had learned before. Surely, students should have similar opportunities. Some of today's players of computer games do have such opportunities. However, the games in which they immerse themselves are not designed to be optimal teachers. Perhaps we need games that have built-in tools like the Process Explorer that Marty Nahemow developed. Such tools could provide just-intime simple explanations of the science or other understanding behind a particular game situation. Perhaps more of the games that are available should allow students to tackle authentic problems that society faces.

Finally, some of what we need to be doing in the world of educational scholarship amounts to a new kind of educational philosophy. We need to keep asking ourselves, as industry keeps producing greater computational power, what the role of humans is in the age of smart machines. The answers may change over time. Assuming essentially infinite computational power, simply identifying a human role clearly makes it a target for automation. Even the professions will struggle (see Susskind \& Susskind, 2015) as computers take over every day professional work like drafting routine contracts, quickly scanning medical test results for signals of disease, and even evaluating progress in recovering from knee injuries. ${ }^{13}$

\footnotetext{
${ }^{13}$ A student-run start-up company being incubated by the University of Pittsburgh has developed a computer system that can observe a person's knee movements and automatically diagnose the results of physical therapy after ACL injuries, for example. Currently doctors and well-trained physical therapists do this work, but the automated system sometimes beats the best of them, and the student team is just getting started.
} 
At present, at least, there are some key human roles. Humans beat machines in attacking novel problems, emergent situations for which we have not prepared intelligent machines. Humans usually beat machines at bridging between bodies of knowledge that rest on differing ontologies. This includes diplomacy, but it also includes mundane things like mediating between consumers and insurance companies. Also, humans still excel at learning to do new jobs during the brief period before they are displaced by new computer systems, though that niche may be eroded as machines get smarter.

Note that none of these three broad areas of human dominance are readily assessed by today's standardized tests. None are covered by the standard curriculum. The Common Core State Standards brush against some of this unsupported space of needed learning, but not as completely as might be optimal. Perhaps the next generation of educational philosophy will address this mismatch.

Education schools that persist as they have existed for about a century likely will shrivel or transform. At the same time, no one who stays aware of how learning occurs and what learning is needed will be short of work in the decades ahead. Thus, the future for educators and educational researchers looks pretty positive. It has been extremely gratifying to be involved in strategic planning and subsequent action of a school of education at this moment of great change.

\section{Broad Lessons Learned}

Throughout this chapter, I have tried to identify some important lessons that can be learned from the patterns of my experience. I conclude now by restating a few of them more generally.

First, we live in a time of rapid change. This creates both problems and opportunities. The key problem for education is that what we need to know keeps changing. We are pretty good at measuring the acquisition of specific knowledge, but we have not fully mastered assessing the ability to learn new content or to apply old knowledge to novel situations. With so much educational policy shaped by a focus on accountability, we push schools to teach what can be measured. This will be a problem until we learn how to measure the ability to figure out what new competence is needed to deal with an emergent life situation, to learn what is needed to have that competence, and to collaborate with others when no one person has all needed competence. Without the right measures, accountability driven by inadequate measures produces pathological results - small changes in what can be measured that do not represent progress toward the real goal. This does not mean that measures have to be perfect. We steer our cars remarkably well without ever investing effort in a perfect decision about how next to move the steering wheel. At the same time, steering fails if we don't look at the road.

While that is mostly a lesson learned by watching others, there is a related personal lesson as well. Life in a time of change requires a sense of adventure. There are dangers to undisciplined adventure, and some adventures end in failure, but there also are dangers in not taking risks. Indeed, sometimes not taking risks is the riskiest behavior of all. As I look back on the careers of my colleagues and my own career, I see some people who stuck to what they had initially learned to do and others who took on new problems when they felt well placed to tackle them, even if they didn't know everything they needed to know and even if it wasn't always the safest thing to do in terms of success in their social situations.

Those who contribute the most in times of rapid change and who are most successful take measured risks when great opportunities arise and try to have fallback plans if they fail in their adventures.

A really important lesson comes from my childhood, as noted near the beginning of this chapter. Getting a strong formation and education requires three things: good schools, community 
support not only for the school but also for general social formation, and personal effort. The lessons I learned watching people shovel sand over slippery spots to help their neighbors were as important as the social lessons learned in kindergarten and later schooling. We need to learn how to teach children by example that a strong system of free enterprise can only survive if it teaches its next generations that neighbors take care of each other even as it rewards business adventures that succeed in improving people's lives.

A broad lesson from my career, beyond just valuing adventure, was that setbacks also are opportunities. Things have not gone smoothly all the time, but even painful events like not getting tenure provided a basis for the start of good things. Related to this lesson is anotherchallenges are opportunities. By finding a way to teach myself some basic artificial intelligence methods using the computer at Stanford, I created some opportunities for collaboration that led to creation of the Intelligent Systems Program. That, in turn, provided a flow of students with talents that greatly expanded the work I could do. This is an instance of another lesson - great things can be done when people work together and complement each other's skills.

Another lesson I have learned is that a reputation for honesty really pays off. When we don't have perfect measures of desired results, we necessarily must rely on honesty of the various partners in new efforts. The Lisp machine project required that people at Xerox PARC, people in the government, and people at Pitt could all trust each other. Without that trust, adventurous action was not possible. With it, we were able to do some good. While I hope I have a reputation of being as good as my word, I deeply believe that for me honesty has been highly rewarding; I could not have had the wonderful experiences I have had without it.
I should make one final point. There were no miracles in any of the work I have done. Like every other academic, I had periods of stress from working very hard. I like to think that I worked on things that matter, but I'm sure that decisions about what to work on were satisficing decisions and that some of the time, I could have skimped on something that in the end did not matter. I hope my family didn't suffer too much because of that.

Some of what looks a bit more audacious, like finding a way to bring artificial intelligence hardware to a number of researchers and putting some of my time into supporting that, required a level of faith in the belief that it was worth the effort to support advances by many colleagues rather than just staying focused on my own research plans. Thinking beyond one's immediate goals has more long-term than short-term payoff. But, we humans live a long time, and preparing for the long term may be wise. What looks audacious to some may look scary to others. Nothing I have been able to accomplish required much courage. What it did require is the conviction that if I act as if the scholarly world is a group endeavor and that we work for each other as well as for ourselves, then others will share that conviction. This is not true universally, but it's true enough. This leads to my last lesson - good things become possible not because everyone is ready to work hard on them but rather because enough people are.

In closing, I again thank all my mentors and companions in the adventures of scholarship. I hope I was as useful to all of you as you were to me. I owe a lot to so many people, including Charles Wrigley, Frank Sim, Gordon Bower, Dick Atkinson, Herb Clark, Chuck Perfetti, Allen Newell, Robert Glaser, Lauren Resnick, Marty Nahemow, and my many other Pittsburgh colleagues. Some were critical influences at one moment while others provided years of 
advice. All were important sources of wisdom, direction, and confidence.

\section{References}

Branson, R. K., Rayner, G. T., Cox, J. L., Furman, J. P., King, F. J., \& Hannum, W .H. (1975). Interservice procedures for instructional systems development. (Vols. 1-5) TRADOC Pam 350-30, NAVEDTRA 106A. Ft. Monroe, VA: U.S. Army Training and Doctrine Command.

Chase, W. G., \& Simon, H. A. (1973). Perception in chess. Cognitive psychology, 4(1), 55-81.

Donnelly, J. E., \& Lambourne, K. (2011). Classroom-based physical activity, cognition, and academic achievement. Preventive Medicine, 52, S36-S42.

Friend, T. (2015, May 18). Tomorrow's Advance Man: Marc Andreessen's plan to win the future. The New Yorker.

Gagné, R. M. \& Briggs, L J. (1974). Principles of Instructional Design (2nd ed.). Holt, Rinehart, and Winston.

Gott, S. P., \& Lesgold, A. M. (2000). Competence in the Workplace: How Cognitive Performance Models and Situated Instruction Can Accelerate Skill Acquisition. In R. Glaser (Ed.), Advances in instructional psychology. Hillsdale, NJ: Erlbaum.

Holahan, C. K., \& Sears, R. R. (1995) The Gifted Group in Later Maturity. Stanford, CA: Stanford University Press.

Kiester, E., Jr. (1993, March). Germany prepares kids for good jobs; we were preparing ours for Wendy's (apprenticeship program). Smithsonian, 23(12), 44+. Retrieved from http://go.galegroup.com/ps/i.do?id=GALE\%7CA13566287\&v=2.1\&u=upitt_main\&it $=\mathrm{r} \& \mathrm{p}=\mathrm{AONE} \& \mathrm{sw}=\mathrm{w} \&$ asid $=\mathrm{f} 96301 \mathrm{aabf} 6 \mathrm{dd} 395684 \mathrm{e} 82 \mathrm{c} 39 \mathrm{~d} 24 \mathrm{f} 720$

Lesgold, A. M. (1984). Acquiring expertise. In Anderson, J. R., and Kosslyn, S. M. (eds.), Tutorials in Learning and Memory. San Francisco: Freeman, San Francisco.

Lesgold, A. M. (2012). Practical issues in the deployment of new training technology. In P. J. Durlach and A. M. Lesgold (Eds.), Adaptive Technologies for Training and Education. New York: Cambridge University Press.

Lesgold, A. M., \& Nahemow, M. (2001). Tools to assist learning by doing: Achieving and assessing efficient technology for learning. In D. Klahr \& S. Carver (Eds.), Cognition and instruction: Twenty-five years of progress. Mahwah, NJ: Erlbaum.

Lesgold, A. M., Resnick, L. B., \& Hammond, K. (1985). Learning to read: A longitudinal study of word skill development in two curricula. In G. Waller and E. MacKinnon (Eds.), Reading Research: Advances in Theory and Practice. New York: Academic Press.

van Merriënboer, J. J .G. (1997). Training Complex Cognitive Skills: A Four-Component Instructional Design Model for Technical Training. Englewood Cliffs, New Jersey: Educational Technology Publications.

Natriello, G., \& Dornbusch, S. M. (1984). Teacher evaluative standards and student effort. New York: Longman.

Sieg, W. (2007). The AProS project: Strategic thinking and computational logic. Logic Journal of IGPL, 15(4), 359-368.

Shulman, L. S. (2005). Signature pedagogies in the professions. Daedalus, 134(3), 52-59.

Stripp, A. (1993). The Enigma machine: Its mechanism and use. In F. H. Hinsley \& A. Stripp, Codebreakers: The Inside Story of Bletchley Park. (Pp. 83-88). Oxford: Oxford University Press.

Suppes, P. (1969). Stimulus-response theory of finite automata. Journal of Mathematical Psychology, 6(3), 327-355. 
Susskind, R., \& Susskind, D. (2015). The Future of the Professions: How Technology Will Transform the Work of Human Experts. OUP Oxford.

Suthers, D., Connelly, J., Lesgold, A., Paolucci, M., Erdosne Toth, E., Toth, J., Weiner, A. (2001). Representational and advisory guidance for students learning scientific inquiry. In K. Forbus and P. Feltovich (Eds.), Smart machines in education. Menlo Park, CA: AAAI Press.

Taylor, Frederick Winslow (1911). The Principles of Scientific Management, New York, NY, USA and London, UK: Harper \& Brothers.

Toth, E. E., Suthers, D. D., and Lesgold, A. M. (2002). Mapping to know: The effects of representational guidance and reflective assessment on scientific inquiry skills. Science Education, 86, 264-286.

Tulving, E., \& Donaldson, W. (1972). Organization of memory. New York: Academic Press.

Van Dusen, D. P., Kelder, S. H., Kohl, H. W., Ranjit, N., \& Perry, C. L. (2011). Associations of Physical Fitness and Academic Performance among Schoolchildren. Journal of School Health, 81(12), 733-740.

Whitehead, A.N. (1929). The aims of education and other essays. Free Press, New York.

Yoncheva, Y. N., Wise, J., \& McCandliss, B. (2015). Hemispheric specialization for visual words is shaped by attention to sublexical units during initial learning. Brain and language, 145, 23-33. 


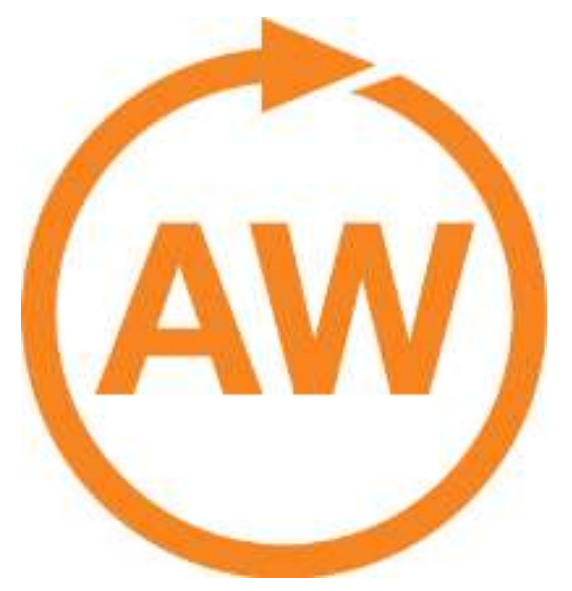

About Acquired Wisdom

This collection began with an invitation to one of the editors, Sigmund Tobias, from Norman Shapiro a former colleague at the City College of New York (CCNY). Shapiro invited retired CCNY faculty members to prepare manuscripts describing what they learned during their College careers that could be of value to new appointees and former colleagues. It seemed to us that a project describing the experiences of internationally known and distinguished researchers in Educational Psychology and Educational Research would be of benefit to many colleagues, especially younger ones entering those disciplines. We decided to include senior scholars in the fields of adult learning and training because, although often neglected by educational researchers, their work is quite relevant to our fields and graduate students could find productive and gainful positions in that area.
Junior faculty and grad students in Educational Psychology, Educational Research, and related disciplines, could learn much from the experiences of senior researchers. Doctoral students are exposed to courses or seminars about history of the discipline as well as the field's overarching purposes and its important contributors. .

A second audience for this project include the practitioners and researchers in disciplines represented by the chapter authors. This audience could learn from the experiences of eminent researchers-how their experiences shaped their work, and what they see as their major contributionsand readers might relate their own work to that of the scholars. The first issue, prepared by Tobias as a sample chapter, was intended for illustrative purposes. Authors were advised that they were free to organize their chapters as they saw fit, provided that their manuscripts contained these elements: 1) their perceived major contributions to the discipline, 2) major lessons learned during their careers, 3) their opinions about the personal and 4) situational factors (institutions and other affiliations, colleagues, advisors, and advisees) that stimulated their significant work.

We hope that the contributions of distinguished researchers receive the wide readership they deserve and serves as a resource to the future practitioners and researchers in these fields. 


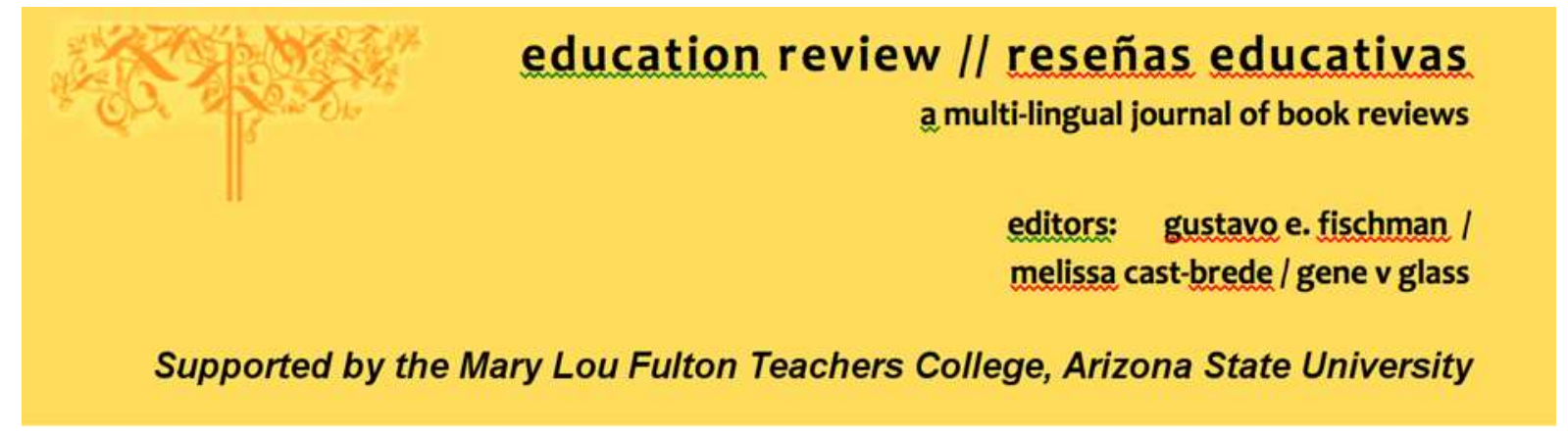

\author{
Acquired Wisdom is \\ Edited by \\ Sigmund Tobias \\ J. D. Fletcher \\ University at Albany \\ Institute for Defense Analyses \\ David C. Berliner \\ University \\ State University of New York \\ Alexandria VA \\ Tempe AZ \\ Advisory Board Members \\ Gustavo Fischman, Arizona State University \\ Arthur C. Graesser III, Memphis State University \\ Teresa 1. McCarty, University of California Los Angeles \\ Kevin Welner, Colorado State University
}

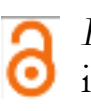

Education Review/Reseñas Educativas/Resenhas Educativas is supported by the edXchange initiative's Scholarly Communications Group at the Mary Lou Fulton Teachers College, Arizona State University. Copyright is retained by the first or sole author, who grants right of first publication to the Education Review. Readers are free to copy, display, and distribute this article, as long as the work is attributed to the author(s) and Education Review, it is distributed for non-commercial purposes only, and no alteration or transformation is made in the work. More details of this Creative Commons license are available at http://creativecommons.org/licenses/by-nc-sa/3.0/. All other uses must be approved by the author(s) or Education Review. Education Review is published by the Scholarly Communications Group of the Mary Lou Fulton Teachers College, Arizona State University.

Please contribute reviews at http://www.edrev.info/contribute.html.

Connect with Education Review on Facebook (https://www.facebook.com/pages/Education-Review/178358222192644) and on Twitter @EducReview 